\title{
๖The Scale and Activity of Symmetric Instability Estimated from a Global Submesoscale-Permitting Ocean Model
}

\author{
Jihai Dong,${ }^{\mathrm{a}, \mathrm{b}}$ Baylor FoX-Kemper, ${ }^{\mathrm{c}}$ Hong Zhang, ${ }^{\mathrm{d}}$ ANd ChANGMing Dong ${ }^{\mathrm{a}, \mathrm{b}}$ \\ ${ }^{a}$ School of Marine Sciences, Nanjing University of Information Science and Technology, Nanjing, Jiangsu, China \\ ${ }^{\mathrm{b}}$ Southern Marine Science and Engineering Guangdong Laboratory (Zhuhai), Zhuhai, Guangdong, China \\ ${ }^{\mathrm{c}}$ Department of Earth, Environmental, and Planetary Sciences, Brown University, Providence, Rhode Island \\ ${ }^{\mathrm{d}}$ Jet Propulsion Laboratory, California Institute of Technology, Pasadena, California
}

(Manuscript received 15 July 2020, in final form 22 February 2021)

\begin{abstract}
Symmetric instability (SI) extracts kinetic energy from fronts in the surface mixed layer (SML), potentially affecting the SML structure and dynamics. Here, a global submesoscale-permitting ocean model named MITgcm LLC4320 simulation is used to examine the Stone linear prediction of the maximum SI scale to estimate grid spacings needed to begin resolving SI. Furthermore, potential effects of SI on the usable wind work are estimated roughly: this estimate of SI "activity" is useful for assessing if these modes should be resolved or parameterized. The maximum SI scale varies by latitude with median values from 568 to $23 \mathrm{~m}$. Strong seasonality is observed in the SI scale and activity. The median scale in winter is $188 \mathrm{~m}$ globally, 2.5 times of that of summer $(75 \mathrm{~m})$. SI is more active in winter: $15 \%$ of the time compared with $6 \%$ in summer. The strongest SI activity is found in the western Pacific, western Atlantic, and Southern Oceans. The required grid spacings for a global model to begin resolving SI eddies in the SML are $24 \mathrm{~m}$ (50\% of regions resolved) and $7.9 \mathrm{~m}(90 \%)$ in winter, decreasing to $9.4 \mathrm{~m}(50 \%)$ and $3.6 \mathrm{~m}(90 \%)$ in summer. It is also estimated that SI may reduce usable wind work by an upper bound of $0.83 \mathrm{~mW} \mathrm{~m}^{-2}$ globally, or $5 \%$ of the global magnitude. The sensitivity of these estimates to empirical thresholds is provided in the text.
\end{abstract}

KEYWORDS: Eddies; Fronts; Instability; Potential vorticity; Oceanic mixed layer; Ocean models

\section{Introduction}

The ocean surface mixed layer (SML) is of significance for air-sea energy and material exchanges. Different processes, including surface waves, Langmuir circulation, vertical convection, and submesoscale processes are capable of changing thermodynamic and kinetic structures of the SML, filtering and modulating air-sea exchanges (e.g., Large et al. 1994; Melville 1996; Qiao et al. 2004; Thorpe 2004; Fox-Kemper et al. 2008; Belcher et al. 2012; Li and Fox-Kemper 2017). As these processes are not resolved by current ocean climate models, parameterizations of the processes in the SML have been proposed and some have been implemented (e.g., Fox-Kemper et al. 2008, 2011; Noh et al. 2016; Qiao et al. 2016; Li et al. 2016; Bachman et al. 2017). The focus of this work is an estimate of the scale and potential impacts, or activity, of symmetric instability (SI), in order to determine the potential value of implementing the Bachman et al. (2017) parameterization or another SI parameterization, the cost of resolving SI, and what resolution of models would benefit from parameterizing SI.

Recent progress has been remarkable in submesoscale oceanography, i.e., the study of spatial scales of $0.01-10 \mathrm{~km}$ and temporal scales of hours to days, or the smallest scales where horizontal gradients and planetary rotation play a leading role. Submesoscale processes have been demonstrated to be ubiquitous in $500 \mathrm{~m}-2 \mathrm{~km}$ resolution models of the SML (e.g., Capet et al. 2008; Su et al. 2018), with small curvy features in

¿ Denotes content that is immediately available upon publication as open access.

Corresponding author: Changming Dong, cmdong@nuist.edu.cn fronts and filaments that are often attributed to baroclinic mixed layer instability (MLI; Boccaletti et al. 2007). MLI potentially occurs when a front or filament provides a horizontal density gradient and vertical shear in the SML, and MLI extracts potential energy from these features for kinetic and potential energy of the submesoscale eddies that form. Given that the scale of the fastest-growing MLI is close to the local deformation radius in the SML (i.e., $L \sim N H / f, N$ is the buoyancy frequency in the SML, $H$ is the SML thickness, $f$ is the local Coriolis parameter), MLI spatial scales vary from 1 to $10 \mathrm{~km}$, requiring a model horizontal grid spacing of $0.55 \mathrm{~km}$ to capture $90 \%$ of regions globally in all seasons (Dong et al. 2020b). Hence, submesoscale eddies generated by MLI can be mostly resolved by current-capability nested models, permitted in a few leading-edge global models (e.g., Capet et al. 2008; Mensa et al. 2013; Rocha et al. 2016a,b; Sasaki et al. 2017; Su et al. 2018; Dong and Zhong 2018; Dong et al. 2020a), and studied in specialized observations (e.g., Callies et al. 2015; Buckingham et al. 2016; Sarkar et al. 2016; Viglione et al. 2018; Little et al. 2018; Yu et al. 2019a; Zhang et al. 2021).

Another mechanism creating SML submesoscales is SI (Hoskins 1974; Bennetts and Hoskins 1979). SI can occur when the Ertel potential vorticity (PV),

$$
q=(f \mathbf{k}+\nabla \times \mathbf{u}) \cdot \nabla b,
$$

is anticyclonic, ${ }^{1}$ i.e., has an opposite sign to the local Coriolis parameter (Hoskins 1974; Haine and Marshall 1998; Haney et al. 2015), namely,

\footnotetext{
${ }^{1}$ Note that anticyclonic PV does not imply anticyclonic relative vorticity.
} 


$$
f q<0 .
$$

Here, $\nabla=(\partial / \partial x) \mathbf{i}+(\partial / \partial y) \mathbf{j}+(\partial / \partial z) \mathbf{k}$ is the horizontal gradient operator, $\mathbf{u}$ is the three-dimensional velocity field, and $b=-g \rho / \rho_{0}$ is the buoyancy $\left(g=9.8 \mathrm{~m} \mathrm{~s}^{-2}\right.$ is the gravitational acceleration, $\rho_{0}=1024 \mathrm{~kg} \mathrm{~m}^{-3}$ is the seawater density constant). In this work, Eq. (2) is applied for investigating SI. A recent study has suggested that Eq. (2) is modified by a factor when the local radius of the curvature becomes comparable to the local deformation radius (Buckingham et al. 2021a,b), but this additional step is not taken in the estimate here. Considering a front under geostrophic balance, $\mathrm{PV}$ is simplified under thermal wind balance,

$$
f q=f \zeta_{a} b_{z}-\left|\nabla_{h} b\right|^{2}
$$

Here, $\zeta_{a}=f-u_{y}+v_{x}$ is the vertical component of the absolute vorticity, $\nabla_{h} b$ is the horizontal buoyancy gradient which always decreases $f q$. When the vertical stratification, $N^{2}=b_{z}$, is reduced by vertical convection or mixing, $f q$ can become negative. SI tends to quickly restore PV to marginal stability (i.e., zero) through mixing into the pycnocline, but under continued surface forcing toward anticyclonic PV, forced symmetric instability can persist (Thomas and Taylor 2010). MLI can occur even when PV $>0$, which together with Eq. (3) implies that SI is associated with stronger (i.e., larger horizontal buoyancy gradient) fronts than MLI. Many studies have shown the SML possesses SI in the presence of strong horizontal buoyancy gradients (D'Asaro et al. 2011; Thomas et al. 2013; Haney et al. 2015; Ramachandran et al. 2018; Savelyev et al. 2018; Viglione et al. 2018; Buckingham et al. 2019; Du Plessis et al. 2019; Yu et al. 2019b). SI are also potentially present in the bottom boundary layer (Wenegrat and Thomas 2020; Yankovsky et al. 2020) as are MLI (Wenegrat et al. 2018a; Dong et al. 2020b). Because frontal strength is a strong function of model grid spacing (Fox-Kemper et al. 2011), very high-resolution models or observations are needed to assess the likelihood and prevalence of fronts strong enough for SI to form, while the resolution for resolving the dynamics of the SI themselves is somewhat finer still.

MLI extracts background potential energy to grow but often transfers kinetic energy toward larger scales (i.e., inverse cascade; Callies et al. 2016; Dong et al. 2020a; Schubert et al. 2020), although it can contribute to the forward cascade of total energy (Capet et al. 2008; Dong et al. 2020a). By contrast, SI mainly extracts kinetic energy from geostrophic fronts and transfers kinetic energy to smaller scales, contributing to local mixing (Taylor and Ferrari 2009; Buckingham et al. 2019) and effectively reducing usable wind work (i.e., the rate of kinetic energy increase in coherent motions due to down-front winds) done on fronts under forced SI (Thomas and Taylor 2010).

Overall, SI tends to reduce anticyclonic PV, restratify the SML, redistribute tracers along isopycnals in the deeper part of the SML (Bachman et al. 2017), and reduce usable wind work (Thomas and Taylor 2010). SI spatial scales are $O(100) \mathrm{m}$ in the SML, much smaller than MLI, thus SI is not resolved even in most current regional models, much less climate models. Parameterizations have been proposed to include the impacts of SI (e.g., Lindstrom and Nordeng 1992; Balasubramanian and Yau 1994; Fei et al. 2011; Bachman et al. 2017; Yankovsky et al. 2020), although they are not commonly in use (Buckingham et al. 2019).

Despite fundamental understanding of SI dynamics and proposed parameterizations, characteristics and impacts of SI from a global perspective remain unclear, as global model resolution has been insufficient to estimate the likelihood of fronts that are strong enough to trigger SI. Here, based on a submesoscale-permitting global model simulation [MITgcm LLC4320, a nominal 2-km horizontal grid spacing, described in the appendix of Rocha et al. (2016b)], this work analyzes the scale and activity of SI globally and investigates potential impacts of SI on the usable wind work. The rest of the paper is organized as follows: section 2 describes the basic theory related to SI; section 3 presents the model and reanalysis data used in the work; section 4 analyzes the spatiotemporal characteristics of SI globally, including its scale and activity, and investigates the potential impacts of SI on the usable wind work; the last section is the discussion and conclusions.

\section{Basic theory of symmetric instability}

\section{a. Maximum scale of symmetric instability}

SI can be regarded as a combination of gravitational and centrifugal instabilities, with perturbations growing and moving slantwise mainly along density surfaces, rather than vertically or horizontally (Haine and Marshall 1998). As shown by the theory of Stone (1966), SI spans a band of unstable wavelengths over which the growth rate increases slowly with wavenumber, which is quite different from the baroclinic instability that is more typified by a most unstable wavenumber (also see Stamper and Taylor 2017). Nevertheless, SI still has a characteristic wavelength which is the maximum wavelength of the unstable modes, which relates to the minimum resolution to potentially resolve SI. For a flow under thermal wind balance, the maximum SI scale, namely, the maximum wavelength, is found from linear theory under nonhydrostatic, ageostrophic dynamics as (Stone 1966)

$$
L=2 \frac{U}{f} \sqrt{1-\mathrm{Ri}_{b}},
$$

where $\mathrm{Ri}_{b}=N^{2} f^{2} /\left|\nabla_{h} b\right|^{2}$ is the balanced Richardson number of a uniformly geostrophically sheared $(d U / d z=U / H=$ constant) and stratified $\left(N^{2}\right)$ SML background state. Neglecting the horizontal component of planetary vorticity, SI is only unstable when this balanced Richardson number is less than 1 which is equivalent to the background potential vorticity being anticyclonic (negative in the Northern Hemisphere, positive in the Southern Hemisphere). In a positive zonal shear flow, including the full planetary rotation effects tends to result in greater activity and tendency toward instability, especially near the equator (Jeffery and Wingate 2009).

In the SML, $U$ is taken as the magnitude of the shear-the difference of the alongfront flow between the surface and bottom of the SI layer $H$ (see section 2c), which can be calculated using the thermal wind relationship as 


$$
U=\frac{1}{f} \int_{-H}^{0}\left|\nabla_{h} b\right| d z .
$$

Here, $\left|\nabla_{h} b\right|$ is the cross-front buoyancy gradient. To manage issues related to sampling near-inertial oscillations, only geostrophic shear is considered for the estimation of the SI scale in this work, although ageostrophic shear effects may be important (Thomas 2012; Haney et al. 2015). The model used in this work has a grid spacing near $2 \mathrm{~km}$ and has many ageostrophic currents with Rossby numbers significantly larger than 1. Nevertheless, the ageostrophic currents are excluded for the estimation, since the Stone (1966) SI theory is based on geostrophic balance of the background flow, and a general estimate without undue complications from ageostrophic currents and their time variation on SI is the primary goal.

The balanced Richardson number for SI to dominate SML instabilities is bounded between $0.25 \leq \mathrm{Ri}_{b} \leq 0.95$ (Stone 1966). For simplicity, $\mathrm{Ri}_{b}$ is directly taken as a constant, $\mathrm{Ri}_{b}=$ 0.95 to give a lower bound of the SI scale (the largest unstable scale being slightly less than 4 times larger over the $0.25-0.95$ range of $\mathrm{Ri}_{b}$ ) - the lower bound scale is also the scale of those SI that are present under marginal conditions, i.e., the strongest stratification and weakest horizontal gradients where SI may dominate. In summary, the SI scale in the SML is estimated as

$$
L=\frac{0.45}{f^{2}} \int_{-H}^{0}\left|\nabla_{h} b\right| d z .
$$

The choice of $\mathrm{Ri}_{b}=0.95$ also has a more practical meaning. The SML in the real ocean tends to stay near a neutral state with $\mathrm{Ri}_{b} \sim 1$ and $\mathrm{PV} \sim 0$ due to restratification processes including SI (Bachman et al. 2017) and geostrophic adjustment (Tandon and Garrett 1994, 1995), especially at frontal regions focused here, despite other processes such as MLI, solar, and wind-driven restratification by upfront winds can lead to much larger Ri than 1 (Fox-Kemper et al. 2008; Thomas et al. 2008; Haney et al. 2012) and the somewhat distant onset of shear turbulence at $\mathrm{Ri}=0.25$. So, $\mathrm{Ri}_{b}=0.95$ is within the range of achievable states of the ocean on an hour-by-hour basis. Nevertheless, questions remain for choosing a suitable $\mathrm{Ri}_{b}$ for $\mathrm{SI}$ dominance, since the value of 0.95 is quite close to 1 . As shown by Stamper and Taylor (2017), a clear growing band of SI can still be observed when $\mathrm{Ri}_{b}=0.75$, but not $\mathrm{Ri}_{b}=1$. To give an estimate of the scale relatively closer to the real ocean, we use the larger $\mathrm{Ri}=0.95$ for the estimation.

\section{b. Buoyancy fluxes related to potential vorticity evolution}

The PV evolution equation is

$$
\frac{\partial q}{\partial t}=-\nabla \cdot \mathbf{J}
$$

where $\mathbf{J}$ is composed of the advective, frictional, and diffusive PV fluxes (aka J vector), respectively,

$$
\mathbf{J}=\mathbf{u} q+\nabla b \times \mathbf{F}-(f \mathbf{k}+\nabla \times \mathbf{u}) \frac{D b}{d t} .
$$

Here, $\mathbf{F}$ represents external forces including frictional and nonconservative body forces and parameterizations of momentum fluxes by unresolved turbulence, while $\mathrm{Db} / \mathrm{d} t$ includes diffusive fluxes and parameterizations of unresolved turbulent buoyancy fluxes (Bodner and Fox-Kemper 2020).

Integrating Eq. (8) vertically over a control volume bounded by isopycnal surfaces yields the result that the PV flux at the sea surface can reduce $f q$ toward negative values and sustain forced SI when (Thomas 2005; Bachman et al. 2017)

$$
f \mathbf{k} \cdot\left[\nabla b \times \mathbf{F}-(f \mathbf{k}+\nabla \times \mathbf{u}) \frac{D b}{d t}\right]>0 .
$$

The PV flux resulting from the vertical momentum fluxes in $\mathbf{F}$, whose surface boundary condition must match the wind stress in equilibrium, is analogous in effect on PV to a surface buoyancy flux (Thomas 2005), so it is convenient to consider a combination of the Ekman buoyancy flux and the surface buoyancy flux,

$$
F=\mathrm{EBF}+B_{0}>0,
$$

where EBF is the Ekman buoyancy flux related to Ekman transport across tilted density isopycnals near the surface ( $\zeta$ is the vertical relative vorticity),

$$
\mathrm{EBF}=\frac{\boldsymbol{\tau}_{w} \times \mathbf{k}}{\rho_{0}(f+\zeta)} \cdot \nabla_{h} b,
$$

and $B_{0}$ is the buoyancy flux caused by sea surface cooling (radiative, latent, or sensible) combined with the buoyancy associated with the salinity change due to the removal of freshwater by evaporation,

$$
B_{0}=B_{T}+B_{S}=g \alpha \frac{Q_{\text {net_heat }}}{\rho_{0} C_{P}}+g \beta(\mathrm{EP}) S .
$$

Here, $\boldsymbol{\tau}_{w}$ is the wind stress, $\alpha$ is the thermal expansion coefficient, $Q_{\text {net_heat }}$ is the net surface heat flux, $C_{P}=4200 \mathrm{~J} \mathrm{~kg}^{-1}{ }^{\circ} \mathrm{C}^{-1}$ is the seawater specific heat capacity, $\beta$ is the saline contraction coefficient, EP is the net freshwater exchange due to evaporation and precipitation (here the convection is for ocean loss of heat with positive $Q_{\text {net_heat }}$ or loss of freshwater with positive EP), and $S$ is the sea surface salinity. The EBF calculation of Eq. (11) includes the contribution of the vertical vorticity at submesoscale frontal regions. However, it is an approximate expression and biases may arise due to the curvature vorticity when fronts become unstable and curving (Wenegrat and Thomas 2017). Stratification potentially decreases and horizontal buoyancy gradients potentially increase when EBF is positive, $\mathrm{EBF}>0$, which happens under down-front winds that move denser, less-buoyant water over buoyant water, causing vertical convection and SI. On the other hand, buoyancy loss occurring by surface cooling or evaporation also leads to vertical convection and/or SI. As a result, both processes tend toward lower $\mathrm{Ri}_{b}$, anticyclonic PV and in favor of forcing SI in the SML.

\section{c. Sublayers of symmetric instability}

SI has been studied in large-eddy simulations (LES) resolving both SI and the turbulence cascade to smaller scales 


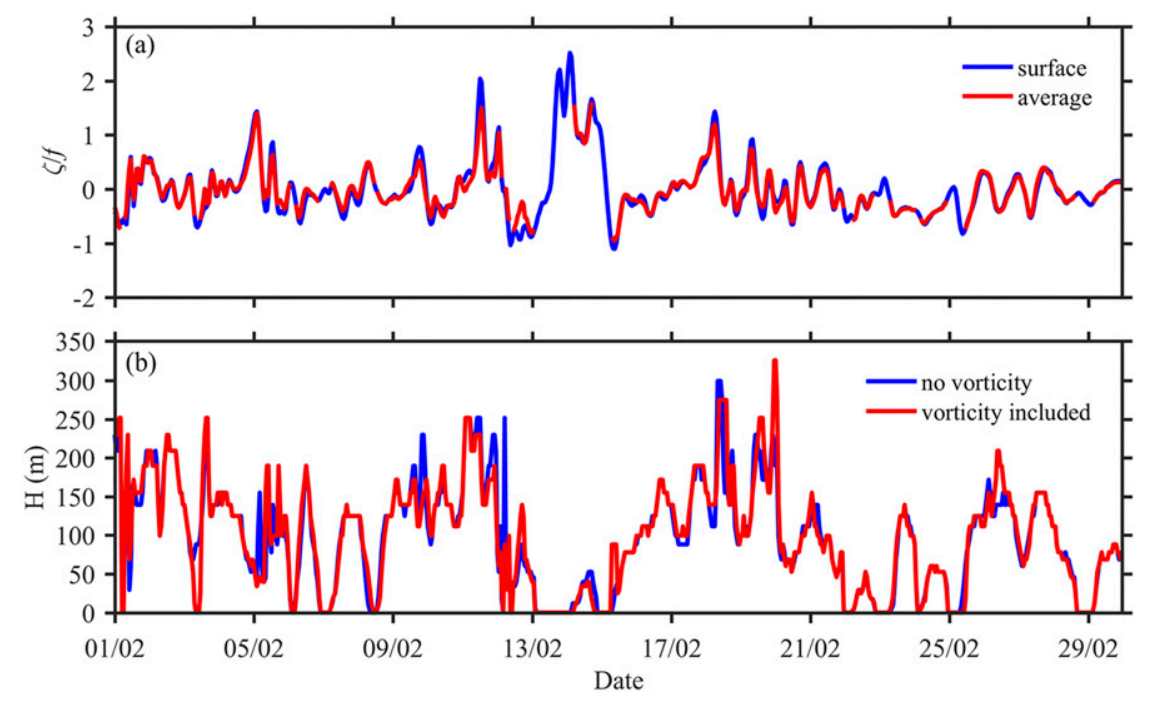

FIG. 1. Time series of (a) the normalized vertical vorticity $\zeta / f$ at surface (blue) and averaged within the SI layer (red), and (b) the SI layer depth calculated based on the bulk PV equation with and without vertical vorticity at the Kuroshio Extension region in February.

under both EBF $>0$ and $B_{0}>0$ (e.g., Taylor and Ferrari 2010; Thomas et al. 2013; Haney et al. 2015; Bachman et al. 2017). As discussed by Bachman et al. (2017), the characteristics of SI under EBF and $B_{0}$ of opposite signs are less well understood (although these conditions are common in the real world!). This paper focuses on the previous SI theory where EBF $>0$ and $B_{0}>0$ occur together.

Taylor and Ferrari (2010) divide the SI effects into two distinct sublayers that are generated as SI responds to the surface buoyancy forcing and Ekman buoyance flux. A nearsurface convective layer is dominated by vertical convection and mixing. Below the convective layer, a layer dominated by slantwise SI motions along isopycnals restratifies and homogenizes PV along isopycnals. Following Bachman et al. (2017), here the total depth of the base below these two sublayers, $H$, is determined as the depth where the bulk PV becomes positive, which also indicates the deepest penetration depth of the unstable SI modes (Haney et al. 2015),

$$
q_{\text {bulk }}=\frac{f}{|f|}\left(f \Delta b+\langle\zeta\rangle \Delta b+\Delta u\left\langle\frac{\partial b}{\partial y}\right\rangle-\Delta v\left\langle\frac{\partial b}{\partial x}\right\rangle\right)>0 .
$$

Here, $\zeta$ is the vertical relative vorticity, $\Delta$ denotes the difference between the surface value and the value at a given depth, the angle bracket denotes a depth average over the same depth range. Note that the bulk PV here excludes the effect from the sign of $f$, and we will use this PV definition hereafter for consistency. Hence, the SML favors SI when PV is negative. Differing from the formulation in Bachman et al. (2017), the bulk PV here includes the contribution from the vertical relative vorticity, $\langle\zeta\rangle \Delta b$, as $\zeta$ is comparable to $f$ consistent with the large gridscale Rossby number in the model simulation used here (e.g., Su et al. 2018). A depth averaged $\zeta$ is applied here since $\zeta$ changes slightly across the two sublayers (Fig. 1a). Figure 1b shows that neglecting the $\zeta$ contribution as
Bachman et al. (2017) recommend sometimes results in noticeable differences in $H$, despite typical consistency. Here, $\zeta$ is available for analysis, and unlike in the parameterization formulation of Bachman et al. (2017) there are no issues of numerical instability in offline analysis, so $\zeta$ is included.

Once $H$ is known, the convective layer depth $h$, the depth where temperature above tends toward vertical uniformity, can be estimated from a quartic equation (Thomas et al. 2013),

$$
\left(\frac{h}{H}\right)^{4}-c^{3}\left(1-\frac{h}{H}\right)^{3}\left[\frac{w_{*}^{3}}{U^{3}}+\frac{u_{*}^{2}}{U^{2}} \cos \theta_{w}\right]^{2}=0
$$

Here, $c=14$ is an empirical constant, $w_{*}=\left(B_{0} H\right)^{1 / 3}$ is the convective velocity due to surface buoyancy loss, $u_{*}=$ $\left(\left|\boldsymbol{\tau}_{w}\right| / \rho_{0}\right)^{1 / 2}$ is the friction velocity, and $\theta_{w}$ is the angle between wind vectors and the direction of vertical geostrophic shear (i.e., the axial direction of a buoyancy front). SI is increasingly important when $h$ is smaller than $H$, but SI is negligibly different from ordinary convection when $h / H \sim 1$. When $h \sim$ $H$, vertical convection dominates nearly the whole of the $H$ layer leaving no room for SI effects. Here, an empirical quantitative criterion is used to indicate important SI of $(H-h) / H \geq 0.05$. In the following, this criterion will be used to find where SI would exist and be active, and the sensitivity is also discussed by changing the criterion as 0.01 and 0.1 in section $4 \mathrm{c}$.

We note that $H$ depends on the model having a surface layer of negative PV, which occurs as a result of buoyancy forcing and Ekman buoyancy flux [Eqs. (9) and (10)], and that SI will restratify and mix so as to eliminate negative PV. The SI scale is much smaller than the model grid here, so this elimination of negative PV by SI does not occur in this model. Thus, it is important to consider both negative PV which allows SI, and the tendency toward negative PV which indicates forced SI. 
The former will tend to be overestimated in this model, as SI is neither resolved nor parameterized in this model.

\section{Model and reanalysis data}

\section{a. Model data}

The model data were simulated by using the Massachusetts Institute of Technology General Circulation Model (MITgcm) on a latitude-longitude polar cap (LLC) grid (Menemenlis et al. 2008; Forget et al. 2015; Rocha et al. 2016a,b). The model simulation, named as LLC4320, has a grid spacing of $1 / 48^{\circ}$ globally with 90 vertical layers. The vertical layer spacing is refined near surface, increasing gradually from $1 \mathrm{~m}$ at the surface to about $15 \mathrm{~m}$ around $150 \mathrm{~m}$ in the upper layer. The atmospheric forcing driving the LLC4320 was the European Centre for Medium-Range Weather Forecasting (ECMWF) analysis with spatiotemporal resolution of $0.14^{\circ}$ and $6 \mathrm{~h}$. The full luni-solar potential was included. The vertical mixing was accomplished by using the $K$-profile parameterization (KPP; Large et al. 1994). The initial model state of the LLC4320 was derived from a $1 / 6^{\circ}$ global ocean state estimate generated by the Estimating the Circulation and Climate of the Ocean (ECCO) Phase II project, and then a set of simulations were successively developed with increasing grid spacings of $1 / 12^{\circ}$, $1 / 24^{\circ}$, and finally $1 / 48^{\circ}$. As of this writing, the LLC4320 simulated 14 months from September 2011 to November 2012. Variables including temperature, salinity and velocity were stored hourly.

This model's output has been widely applied, especially for studying submesoscale processes (e.g., Rocha et al. 2016a,b; Su et al. 2018; Viglione et al. 2018; Dong et al. 2020a). Relatively large submesoscale fronts (around $10 \mathrm{~km}$ ) are well resolved, and some MLI is resolved (at fewer than $50 \%$ of grid points; Dong et al. 2020b), but SI is not expected to be resolved at the vast majority of locations. These resolved submesoscale fronts offer an opportunity to use the LLC4320 for an accurate estimation of SI characteristics, expanding beyond the idealized circumstances of previous estimates (e.g., Thomas and Taylor 2010) or the estimates using coarser resolution global state estimates [a reduction in the total usable wind-work of over $5 \%$ is found by those authors using a coarse resolution $\left(1 / 6^{\circ}\right)$ ECCO state estimate from Wunsch et al. (2009)]. Based on the hourly model data in February and August 2012 including velocity, temperature and salinity, the corresponding horizontal gradients are calculated. Then all these variables are subsampled directly onto a $4^{\circ}$ grid for a global analysis. Equatorial regions (equatorward of $10^{\circ}$ ) are excluded because the small $f$ values preclude geostrophy and the tilted rotation potentially becomes important for SI (Jeffery and Wingate 2009; Colin de Verdière 2012).

\section{b. Reanalysis data}

Consistent with the LLC4320 setup, the atmospheric forcing provided by the ECMWF are used for the calculation of surface buoyancy and momentum fluxes. Variables including 10-m wind speed, heat fluxes, evaporation, and precipitation with spatiotemporal resolution of $0.125^{\circ}$ and $6 \mathrm{~h}$ are retrieved.
The wind stress is calculated as $\boldsymbol{\tau}_{w}=\rho_{\text {air }} C_{d}\left|\mathbf{u}_{w}\right| \mathbf{u}_{w}$, where $\rho_{\text {air }}=1.25 \mathrm{~kg} \mathrm{~m}^{-3}, C_{d}=0.00125$, and $\mathbf{u}_{w}$ are the air density, drag coefficient, and $10-\mathrm{m}$ wind velocity, respectively. Combining the atmospheric forcing from the ECMWF with the buoyancy gradient fields from the LLC4320, EBF can be calculated according to Eq. (11). The buoyancy flux $B_{0}$ is based on Eq. (12) with heat and freshwater fluxes from the ECMWF and sea surface temperature and salinity from the LLC4320.

\section{Maximum scale and activity of symmetric instability}

\section{a. Surface potential vorticity and buoyancy flux}

Based on Eq. (13), the surface bulk PV is calculated in the LLC4320 (i.e., in the shallowest two cells centered at 0.5 and $1.57 \mathrm{~m}$ ). The averaged PV in winter (February in the Northern Hemisphere and August in the Southern Hemisphere, the same below) and summer (August in the Northern Hemisphere and February in the Southern Hemisphere, the same below) is shown in Figs. 2a and 2b. Negative PV within the SML is widespread over the globe in the LLC4320. A strong seasonal variability of $\mathrm{PV}$ is also apparent: in winter, the averaged PV is generally negative (Fig. 2a) but positive in summer (Fig. 2b). The relative likelihood of negative PV in hourly fields resembles the averaged PV distributions (Figs. 2c,d). The relative likelihood is defined as the number of hourly time points $N_{t}$ with negative PV over the whole set of hourly time points in the period $N_{T}$ for each grid point, namely, $N_{t} / N_{T}$. The relative likelihood in winter is $70 \%$ averaged over the globe, and $49 \%$ in summer (the spatial average is always an area-weighted value in this work). Hence, negative PV occurs more frequently in winter, and PV is more easily reduced below zero in winter.

As noted above, it is important to consider both negative PV in the LLC4320 and forcing tending toward negative PV, as forced SI is likely to occur only when both conditions hold. And a lack of SI in the LLC4320 simulation makes the sign of PV alone overestimate the expected occurrence versus a model that resolves or parameterizes their tendency to marginally stabilize themselves. As discussed in section 2b, the surface PV evolution is tightly related to the surface buoyancy fluxes, $B_{0}$ and EBF. Both fluxes reduce surface PV when they are positive. The monthly averaged $B_{0}$ has obvious seasonality, with positive fluxes in winter when the oceans are warmer than the atmosphere and negative in summer when they are cooler (Figs. 3a,b). The monthly averaged EBF shows latitude dependence with relatively larger values at low latitudes (Figs. 3c,d). According to a comparison with PV distributions in Fig. 2, it can be inferred that the PV variability is mainly dominated by $B_{0}$. Furthermore, the relative likelihood of $B_{0}>0, \mathrm{EBF}>0$ is consistent with that of $\mathrm{PV}<$ 0 , which is higher in winter (Figs. 3e,f). On average, the relative likelihood of the positive buoyancy fluxes in winter is $29 \%$ and $23 \%$ in summer.

Equation (13) shows that PV can be decomposed into two terms, the vertical component related to vorticity and stratification, and the horizontal component related to vorticity and horizontal buoyancy gradients. Negative PV caused by the surface buoyancy flux $B_{0}$ is solely from the vertical component, 

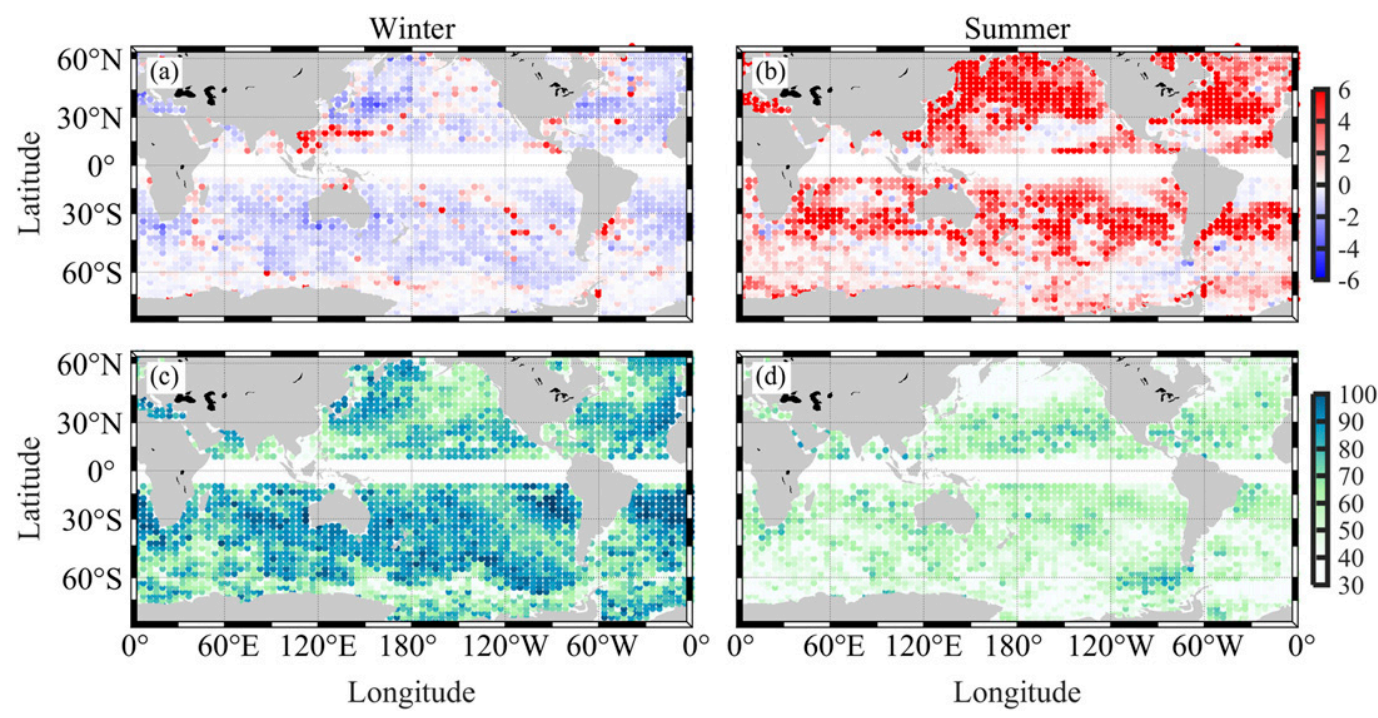

FIG. 2. Spatial distributions of (a),(b) the monthly averaged surface bulk PV $\left(\times 10^{-9} \mathrm{~m} \mathrm{~s}^{-3}\right)$ and (c),(d) the relative likelihood $(\%)$ of PV $<0$. Results in (left) winter (February in the Northern Hemisphere and August in the Southern Hemisphere) and (right) summer (August in the Northern Hemisphere and February in the Southern Hemisphere).

which leads primarily to convective instability without fronts. The buoyancy gradient associated with fronts is necessary to generate negative horizontal component of PV for SI. Even when the surface buoyancy flux $B_{0}$ results in forced SI, a horizontal buoyancy gradient is also required to provide geostrophic shear as an energy source for the SI. Meanwhile, a positive EBF from down-front winds is also necessary here, since this flux provides energy source for sustaining SI.

\section{b. Thickness of the symmetric instability layer}

For each grid point with negative PV, the thickness of the negative-PV layer $H$ can be determined by Eq. (13). The monthly averaged $H$ (Figs. 4a,b) has a similar spatial pattern and consistent seasonal variation with the SML depth based on density or temperature (e.g., de Boyer Montégut et al. 2004) which likewise resembles the convective layer depth $h$ (Figs. 4c,d): all are deep in winter and shallow in summer (Fig. 4). In winter, deep negative-PV layers with a maximum thickness exceeding $150 \mathrm{~m}$ are observed at the northwestern Pacific Ocean, high latitudes of the Atlantic Ocean and Antarctic Circumpolar Current region (ACC) (Fig. 4a). The layer shallows significantly in summer and is generally less than $50 \mathrm{~m}$ (Fig. 4b). Generally, deep $H$ is accompanied by relatively large negative PV (Fig. 1). Quantitatively, the median $H$ in winter is $20 \mathrm{~m}$ in the Northern Hemisphere and $28 \mathrm{~m}$ in the Southern Hemisphere, and decreases to 4.5 and $5.8 \mathrm{~m}$ in summer. Considering uneven area coverage of the grid cells at different latitudes, the median and other percentiles in the paper are determined based on area covered.

Solving the quartic equation of Eq. (14) derives the convective sublayer thickness $h$ (Figs. 4c,d) and the SI-dominant layer $H-h$ (Figs. 4e,f). The $h$ layer is well mixed vertically in temperature and density, and thus is directly comparable to observed SML depths based on vertically homogeneous properties. The action of SI in the deeper sublayer between depths $h$ and $H$ does not tend toward vertically homogeneous temperature or density, only vertically homogeneous $\mathrm{PV}$, but the sublayer shares a very similar pattern and seasonality with the convective sublayer $h$. Both layers vary in accordance with $H$, with thick sublayers ( $h$ and $H-h$ ) in regions where $H$ is deep. Overall, the monthly averaged convective layer thickness ( $h$; Figs. $4 \mathrm{c}, \mathrm{d})$ is greater than the SI-dominated layer thickness $(H-h$; Figs. 4e,f), comprising most of the total $H$ (Figs. 4a,b). Nevertheless, the SI-dominant layer has a remarkable seasonality, which is almost exclusively deep in winter-representing a relatively large fraction of $H$-and hardly observed in summer (Figs. 4e,f).

According to Eq. (14), the SI-dominated layer depends on the relative magnitudes of the buoyancy fluxes (i.e., the Ekman buoyancy flux EBF and the air-sea buoyancy flux $B_{0}$ ) and front intensity (also refer to appendix C of Bachman et al. 2017). Strong fronts tend to generate thick SI-dominated layers due to strong alongfront geostrophic shear in the SML. Given $H$, the ratio, $R_{H}=(H-h) / H$, reflects the relative volume of the SI-dominant layer and the importance of SI quantitatively (Fig. 5). A relatively large $R_{H}$ implies that the impacts of SI on stratification and current intensity should be considered in the SML. The $R_{H}$ is $6 \%$ in summer, but the winter-averaged $R_{H}$ over both hemispheres is $13 \%$. In the following, only where $(H-h) / H \geq 0.05$ is defined as an important SI layer (otherwise, is effectively a purely convective layer).

\section{c. Maximum scale and activity of symmetric instability}

Based on the cross-front buoyancy gradients within $H$, the maximum SI scale is estimated based on Eq. (6). The scale 

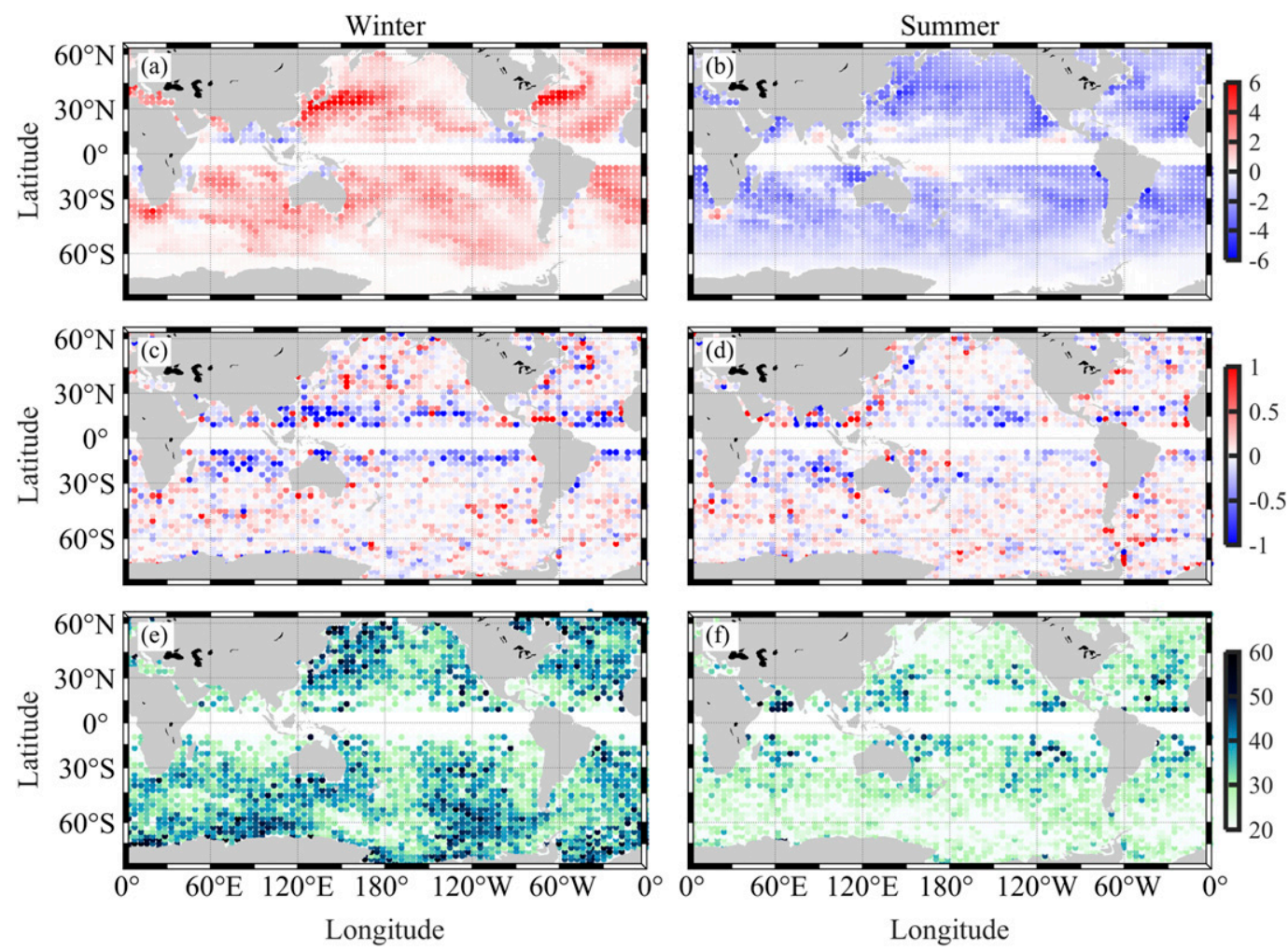

FIG. 3. Spatial distributions of (a),(b) the monthly averaged $B_{0}\left(\times 10^{-7} \mathrm{~m}^{2} \mathrm{~s}^{-3}\right),(\mathrm{c}),(\mathrm{d})$ the monthly averaged $\operatorname{EBF}\left(\times 10^{-7} \mathrm{~m}^{2} \mathrm{~s}^{-3}\right)$, and (e),(f) the relative likelihood (\%) of $B_{0}>0, \mathrm{EBF}>0$. Results in (left) winter (February in the Northern Hemisphere and August in the Southern Hemisphere) and (right) summer (August in the Northern Hemisphere and February in the Southern Hemisphere).

depends on latitude (Figs. 6a,b), varying from several kilometers to less than $10 \mathrm{~m}$. In winter, deep SI layers in the both hemispheres yield relatively large SI scales compared to summertime scales. The relative likelihood of SI events (i.e., where $B_{0}>0$, $\mathrm{EBF}>0,(H-h) / H \geq 0.05$, and bulk $\mathrm{PV}$ is negative) is correspondingly high in winter (Figs. 6c,d), and the SI-dominated layer is relatively thick. The likelihood of SI events in winter can reach $40 \%$ in strongly convective or windy frontal regions such as the southern and western Pacific and Atlantic Oceans.

The SI scale is fairly uniform zonally, so the latitude dependence and seasonality are highlighted using the zonal medians in the two seasons (Fig. 7a). The shaded intervals indicate the 10 th to 90 th percentile range of the SI scale. The median SI scale decreases with latitude, from $568 \mathrm{~m}$ (note that $\mathrm{Ri}_{b}=0.95$ is chosen here; it is $2.2 \mathrm{~km}$ with $\left.\mathrm{Ri}_{b}=0.25\right)$ at low latitudes to $23 \mathrm{~m}\left(89 \mathrm{~m}\right.$ with $\left.\mathrm{Ri}_{b}=0.25\right)$ at high latitudes. Meanwhile, an asymmetry is observed between two hemispheres. The summer SI scale is slightly larger in the Southern Hemisphere than in the Northern Hemisphere, while the winter SI scale is comparable between two hemispheres (Fig. 7a). Overall, the median scale in winter is $188 \mathrm{~m}\left(728 \mathrm{~m}\right.$ with $\left.\mathrm{Ri}_{b}=0.25\right)$ globally, about 2.5 times of that in summer $(75 \mathrm{~m} ; 290 \mathrm{~m}$ with $\left.\mathrm{Ri}_{b}=0.25\right)$.

The seasonal difference is described by a ratio of the scale in summer over winter, namely, $R_{L}=L_{\text {sum }} / L_{\text {win. }}$. Here, $R_{L}$ of the median and 10th and 90th percentile scales are calculated and averaged for analysis (Fig. 7b). It can be observed that the seasonality of the SI scale is more noticeable at midlatitudes. $R_{L}$ is generally between 0.4 and 0.6 in the Southern Hemisphere, but below 0.4 (as low as 0.2) in the Northern Hemisphere. The median SI scale at midlatitudes $\left(20^{\circ}-60^{\circ}\right)$ in summer is $61 \mathrm{~m}$, 2.7 times smaller than the value of $167 \mathrm{~m}$ in winter. Near equatorial and polar regions, the scales are close in winter and summer, since $R_{L}$ is around unity. The ratio difference between two hemispheres also suggests the seasonality is stronger in the Northern Hemisphere. The median winter and summer scales are 187 and $56 \mathrm{~m}$ at midlatitudes of the Northern Hemisphere, but 155 and $65 \mathrm{~m}$ of the Southern Hemisphere.

The SI activity [i.e., where $B_{0}>0, \mathrm{EBF}>0,(H-h) / H \geq$ 0.05 , and bulk PV is negative] by latitude can be found from the zonal likelihood in the different months (Fig. 7c). The SI activity depends on latitude and has weak seasonality at low latitudes but strong seasonality poleward. SI is more active in winter with a typical percentage of $15 \%$ over the globe compared with a proportion of $6 \%$ in summer. Overall, the SI likelihood is $11 \%$ globally over the two months. The SI likelihood is dependent on the thickness ratio $(H-h) / H$. A sensitivity test is conducted here. If the criterion is increased to 0.1 as suggested by Bachman et al. (2017), the likelihood is decreased to $11 \%$ in winter and $4 \%$ in summer with a global value 

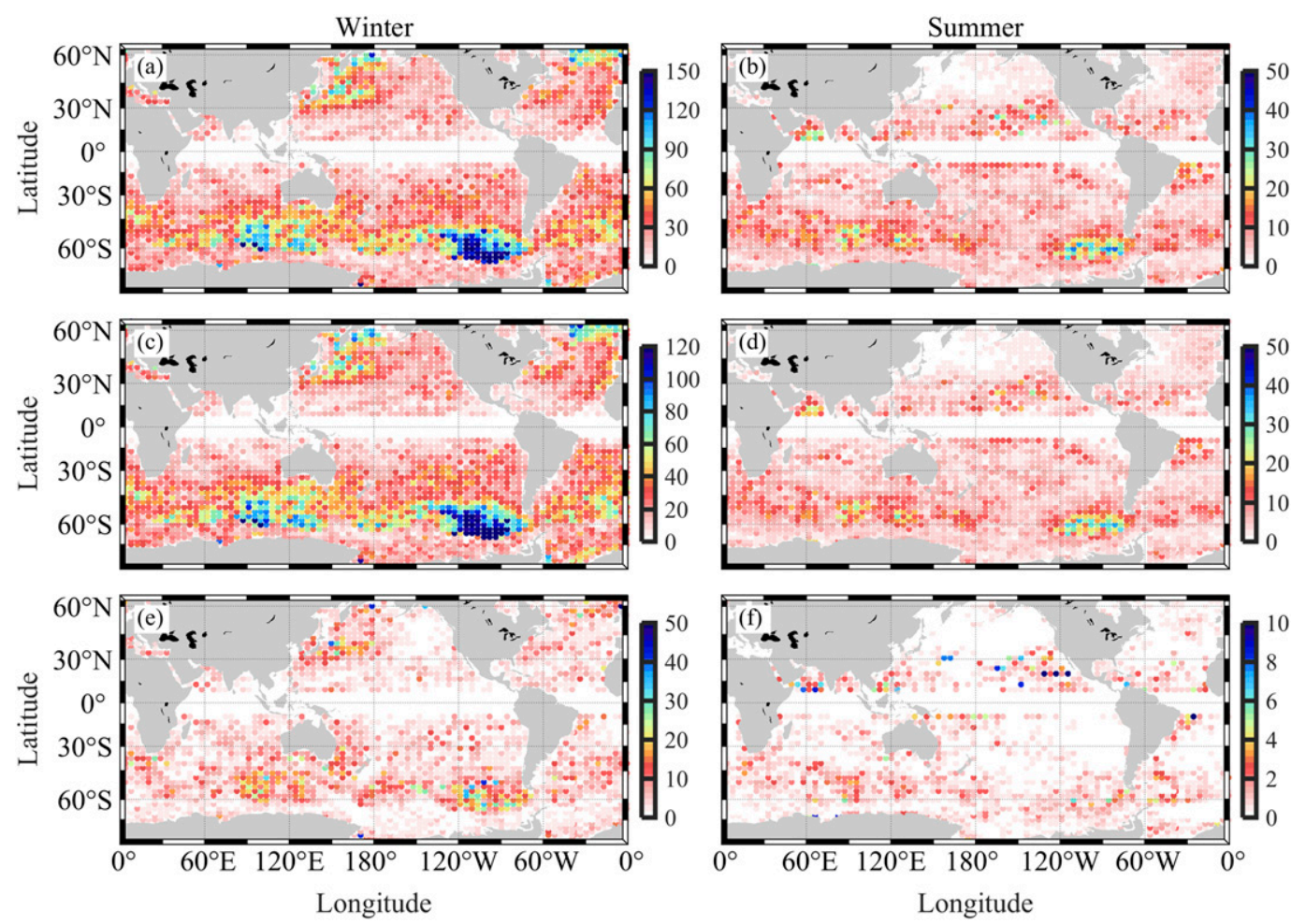

FIG. 4. Spatial distributions of the monthly averaged (a),(b) $H$, (c),(d) $h$, and (e),(f) $H-h$ (m). Results in (left) winter (February in the Northern Hemisphere and August in the Southern Hemisphere) and (right) summer (August in the Northern Hemisphere and February in the Southern Hemisphere).

of $8 \%$. In contrast, the likelihood is increased to $21 \%$ in winter and $12 \%$ in summer with a global value of $16 \%$ if the ratio is decreased to 0.01 .

The scale and activity of SI are tightly correlated, and both are increased in winter. The seasonality can be attributed to different factors including surface buoyancy fluxes, wind strength, and submesoscale activity (insofar as it is resolved in the LLC4320; see Dong et al. 2020b). In winter, stratification in the SML is sharply reduced and the SML is thickened by down-front winds and buoyancy loss due to surface cooling. The weak wintertime stratification makes the baroclinic term [see Eq. (3)] more easily reduce PV below zero and trigger SI. Moreover, submesoscale fronts are reported to be more active in winter (Capet et al. 2008; Callies et al. 2015; Su et al. 2018). The strong horizontal buoyancy gradient of submesoscale fronts also increases the SI activity. Both MLI and SI tend to restratify, and both tend to be more active in wintertime. Simulations resolving both tend to indicate coexistence, or spatiotemporal intermittency between the two types of submesoscale instabilities rather than exclusion of one type in favor of the other (e.g., FoxKemper et al. 2008; Hamlington et al. 2014); simulations of MLI combined with parameterizations of SI, as well as observations of submesoscale variability especially of stratification and PV, can help to determine if this holds globally and seasonally.

\section{d. Potential impacts on usable wind work}

If kinetic energy is increased from the wind work when there exists a down-front wind component, part of the wind work is dissipated by SI triggered by the down-front wind (Thomas and Taylor 2010). Give that the growth of SI can be described by the geostrophic shear production (GSP), the SI dissipation rate $\varepsilon_{\text {SI }}$ is expressed as (Thomas et al. 2013; Bachman et al. 2017; Buckingham et al. 2019)

$$
\varepsilon_{\mathrm{SI}}=\mathrm{GSP}=\left\{\begin{array}{lc}
0, & z=0 \\
\left(\mathrm{EBF}+B_{0}\right) \frac{z+H}{H}-B_{0} \frac{z+h}{h}, & -h \leq z<0 \\
\left(\mathrm{EBF}+B_{0}\right) \frac{z+H}{H}, & -H \leq z<-h \\
0, & z<-H
\end{array} .\right.
$$



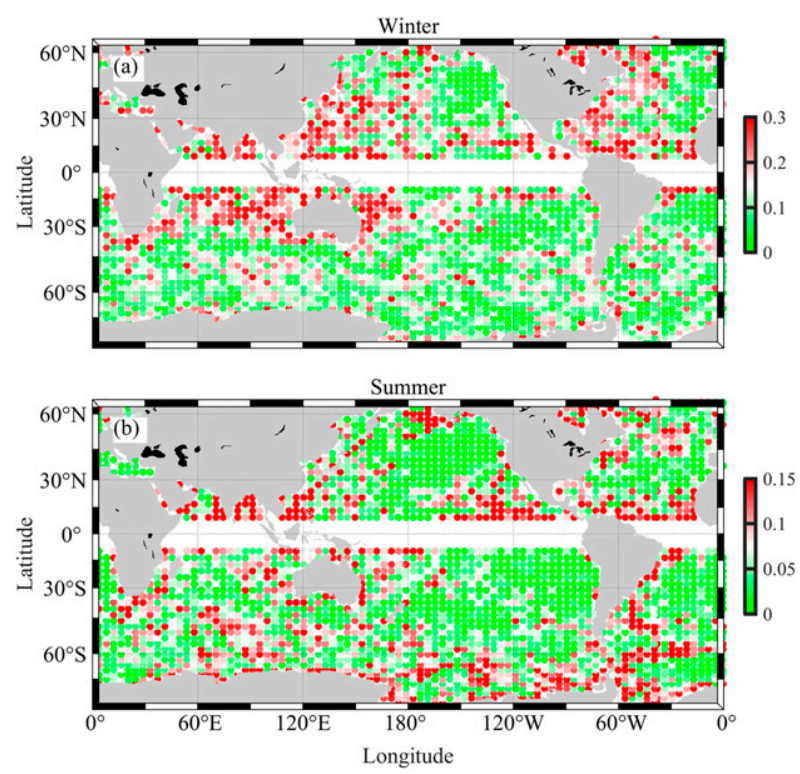

FIG. 5. Spatial distributions of the ratio, $R_{H}=(H-h) / H$ in (a) winter (February in the Northern Hemisphere and August in the Southern Hemisphere) and (b) summer (August in the Northern Hemisphere and February in the Southern Hemisphere).

An integral of the dissipation rate within the SI layer is believed to be an upper bound of the usable wind-work reduction due to SI (an upper bound because part of the dissipation may be directly from the kinetic energy of ocean circulation due to $\left.B_{0}\right)$, namely,

$$
\Delta P=\int_{-H}^{0} \varepsilon_{\mathrm{SI}} d z
$$

Based on the calculated EBF, $B_{0}, H$, and $h$ above, the usable wind-work reduction due to SI, $\Delta P$ is estimated (Fig. 8). Grid points with no SI activity (i.e., satisfying EBF $<0$ or $B_{0}<0$ or $h / H>0.95)$ are excluded from the integral. Not surprisingly, hot spots of the usable wind-work reduction $\Delta P$ up to $5 \mathrm{~mW} \mathrm{~m}^{-2}$ are concentrated at the regions with strong SI activity and are strongly seasonal (Figs. 8a,b). As a comparison, the background wind work,

$$
P=\boldsymbol{\tau} \cdot \mathbf{u},
$$

is calculated using the hourly sea surface wind curl $\boldsymbol{\tau}$ and sea surface velocity $\mathbf{u}$. It is noteworthy that the impact of the sea surface velocity on the wind stress calculation is not considered here, which overestimates the total wind work (Duhaut and Straub 2006; Zhai and Greatbatch 2007; Hughes and Wilson 2008; Zhai et al. 2012) especially at submesoscale-permitting resolutions (Renault et al. 2018). Compared with the monthly averaged background wind work, a relative proportion of the reduced usable wind-work $\Delta P$ up to $40 \%$ is found in subtropical regions (Figs. 8c,d). Over the globe, the total wind-work reduction over the two months considered is $0.22 \mathrm{TW}$, i.e., $0.83 \mathrm{~mW} \mathrm{~m}^{-2}$ on average. The total background wind work globally derived here is $4.23 \mathrm{TW}$, i.e., $16 \mathrm{~mW} \mathrm{~m}^{-2}$ on average [this magnitude is very close to the value of $4.71 \mathrm{TW}$ derived by Flexas et al. (2019) using the same model simulation but one year of data]. Hence, the usable wind-work reduction amounts to a proportion of $5 \%$ compared with the background wind work in this model. For ocean models that include no SI parameterization schemes, the wind-work input to the ocean that is usable is potentially overestimated by up to $5 \%$ globally and $40 \%$ regionally and seasonally.

Buckingham et al. (2019) estimate a dissipation rate of $0.42 \mathrm{~mW} \mathrm{~m}^{-2}$ by SI over the North Atlantic region using the same method applied to a $1-\mathrm{km}$ model at one location and then
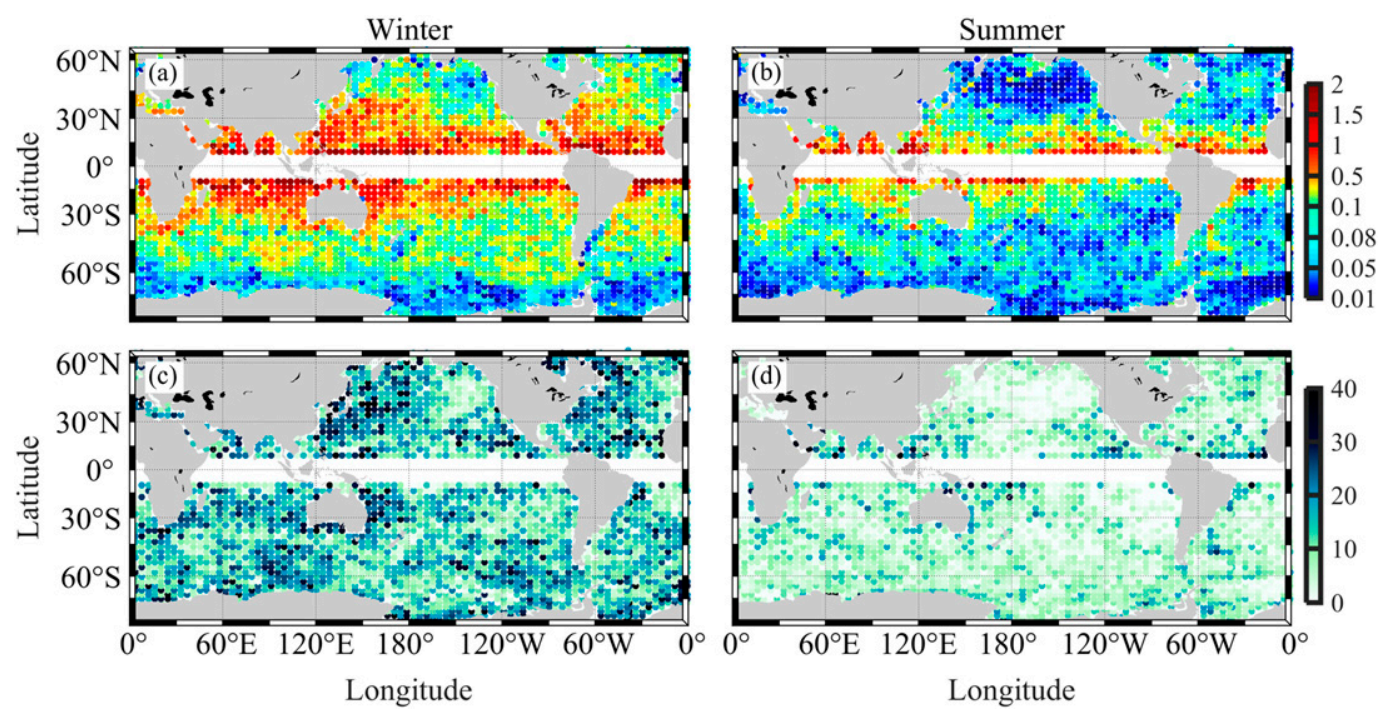

FIG. 6. Spatial distributions of (a),(b) the monthly averaged SI scale (km) and (c),(d) the relative likelihood (\%) of SI. Results in (left) winter (February in the Northern Hemisphere and August in the Southern Hemisphere) and (right) summer (August in the Northern Hemisphere and February in the Southern Hemisphere). 

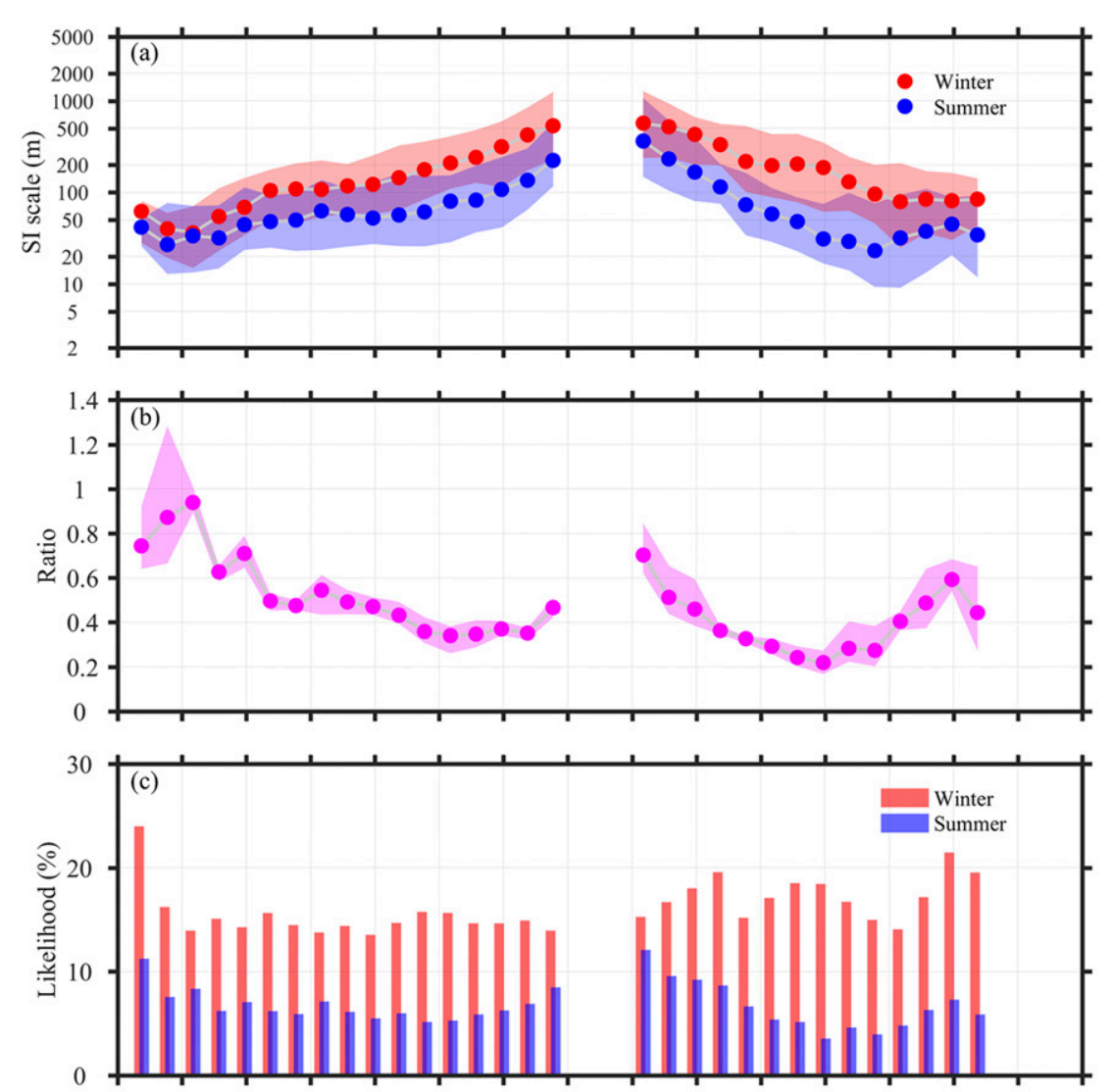

$80^{\circ} \mathrm{S} 70^{\circ} \mathrm{S} 60^{\circ} \mathrm{S} 50^{\circ} \mathrm{S} 40^{\circ} \mathrm{S} 30^{\circ} \mathrm{S} 20^{\circ} \mathrm{S} 10^{\circ} \mathrm{S} 10^{\circ} \mathrm{N} 20^{\circ} \mathrm{N} 30^{\circ} \mathrm{N} 40^{\circ} \mathrm{N} 50^{\circ} \mathrm{N} 60^{\circ} \mathrm{N} 70^{\circ} \mathrm{N} 80^{\circ} \mathrm{N}$ Latitude

FIG. 7. (a) The zonal median scale (winter in red and summer in blue), (b) the averaged scale ratio $R_{L}$, and (c) the relative likelihood (\%; winter in red and summer in blue) of SI. The shaded intervals in (a) denote the 10th and 90th percentile range of the SI scale. The shaded interval in (b) denote the minimum and maximum $R_{L}$ of the median and 10th and 90th percentile scales.

scaling up to the whole basin. They argue a global wind reduction of $10 \%-15 \%$ comparing to the canonical global windwork input into the ocean general circulation of 1 TW by Ferrari and Wunsch (2009) by assuming this rate is an average state of the globe. However, our result shows that this reduction varies remarkably and regionally, following an approximately lognormal distribution (Fig. 8e; Pearson and Fox-Kemper 2018), despite that a close value of $0.38 \mathrm{~mW} \mathrm{~m}^{-2}$ is obtained here including a wider span of data over the northeast Atlantic region. As a comparison, the usable wind-work reduction values derived from this work and Buckingham et al. (2019) are shown as well (red solid and dash lines in Fig. 8). This statistical distribution indicates that it is exceptional for Buckingham et al. (2019) to get a usable wind-work reduction close to the global average, since the log-normality implies that SI occurs intermittently and the average is dominated by large values at a few specific regions and times. Note that the average value is over an order of magnitude larger than the most likely value found at the peak of the distribution. Also, our estimate of the usable wind-work reduction and total wind work consistently derives from the high-resolution simulation, but of course the model resolution is limited and model approximations have likely effects on the outcome. The total wind-work input is much larger compared to the magnitude of the wind-work input into the general circulation due to higher spatiotemporal resolution (Wang and Huang 2004; Flexas et al. 2019). So, a smaller proportion of $5 \%$ is obtained here compared to the one from Buckingham et al. (2019). Ultimately, global usable wind-work reduction estimates will remain approximate-either due to model errors as here or observational lack of representativeness-until submesoscale vector currents and wind stresses can be simultaneously estimated on a near-global basis, probably by next-generation satellites (e.g., Gommenginger et al. 2019).

It should be noted that Eq. (16) on the usable wind-work reduction estimation is based on steady surface forcing (i.e., constant down-front wind and surface buoyancy flux; see Thomas and Taylor 2010). Variable down-front winds may potentially reduce the estimate accuracy as the energetics of SI are modulated by inertial oscillations under variable winds (Thomas et al. 2016). However, the temporal average utilized here tends to eliminate this impact (Thomas et al. 2016). 

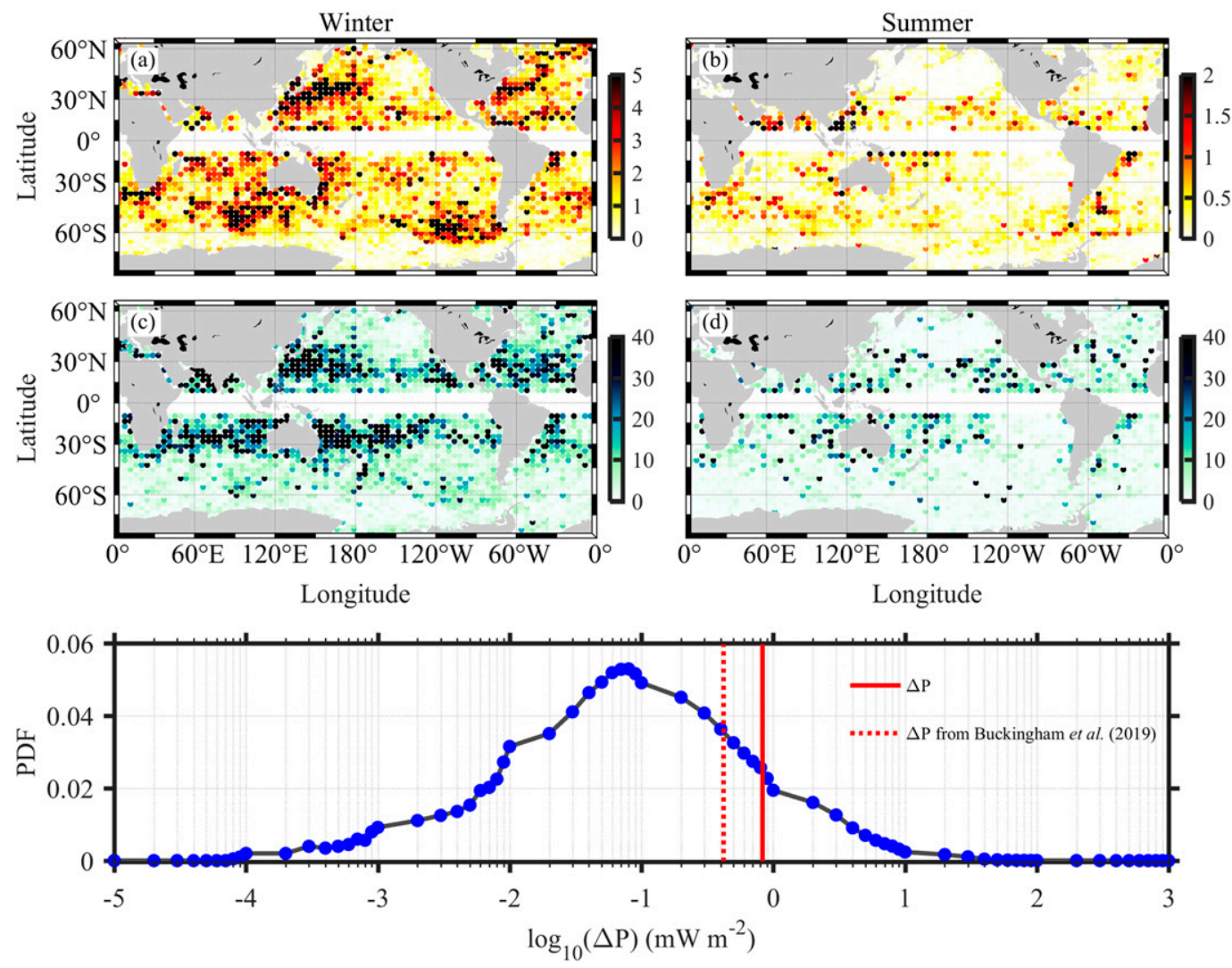

FIG. 8. Spatial distributions of (a),(b) the usable wind-work reduction $\Delta P\left(\mathrm{~mW} \mathrm{~m}^{-2}\right)$ and (c),(d) the proportion (\%) compared with the background wind work. (e) The probability distribution function (PDF) of the hourly usable wind-work reduction in the two months. Results in (a) and (b) are for winter (February in the Northern Hemisphere and August in the Southern Hemisphere) and in (c) and (d) for summer (August in the Northern Hemisphere and February in the Southern Hemisphere). The solid and dashed lines in (e) denote the globally averaged usable wind-work reduction from this work and the value from Buckingham et al. (2019).

Realistically, the rate at which the kinetic energy dissipation occurs under SI is an important aspect of the parameterization (Thomas et al. 2013; Bachman et al. 2017; Buckingham et al. 2019), which will be evaluated in future work where the timeevolving state and feedbacks are included.

\section{Discussion and conclusions}

\section{a. Discussion}

The criterion of negative PV applied here is a general criterion for SI (Hoskins 1974), and it is demonstrated by SIresolving simulations that the PV criterion holds even when the Richardson number criterion fails (Haney et al. 2015). This paper lays the foundation for the application of the SI parameterization scheme proposed by Bachman et al. (2017), so negative bulk PV and layer thickness ratio are used as the criteria here. The likelihood of SI here is surely overestimated when based on negative PV and layer thickness in a model that does not have SI, as SI would tend to eliminate negative PV and restratify the PV-dominated layer. However, the criterion of both $B_{0}>0$ and EBF $>0$ for the forced SI may underestimate its activity. If a more generous criterion of negative surface bulk PV ( $q_{\text {bulk }}<0$ at surface), negative horizontal bulk PV component within $H(\Delta u\langle\partial b / \partial y\rangle-$ $\Delta v\langle\partial b / \partial x\rangle<0$ within $H$ ), and positive combined buoyancy flux $\left(B_{0}+\mathrm{EBF}>0\right)$, is applied, then a global likelihood of $27 \%$ is obtained, more than 2 times larger than the result estimated in this work $(11 \%)$ with the stricter forcing criterion of both $B_{0}>0$ and $\mathrm{EBF}>0$.

Seasonality is one of the important characteristics of submesoscale eddies and fronts in the SML, which has been demonstrated to be tightly related to MLI and the inverse cascade (Mensa et al. 2013; Callies et al. 2015; Dong et al. 2020a). In this work, the submesoscale variability generated by SI is demonstrated to have a strong seasonal variability as well, in scale and activity. As discussed in section 4c, the seasonality of SI is partially regulated by more active wintertime submesoscale fronts resolved in the LLC4320. However, based on an analysis of the MLI scale, Dong et al. (2020b) argue that the MLI scale in summer is much smaller than winter, implying that the submesoscale eddies and fronts in summer may not be resolved by the LLC4320. One may expect an overall increase of the SI activity (higher likelihood) as the model resolution 
increases (more intensive submesoscale fronts resolved, i.e., higher likelihood of EBF >0), and a larger increase of the SI activity in summer (summertime submesoscale fronts resolved) than winter if the model resolution becomes fine enough to resolve MLI totally. MLI tends to restratify the mixed layer, potentially reducing the thickness of the SI layer, while at the same time generating intensive submesoscale fronts. So, it is hard to tell how the maximum SI scale $L$, the usable wind-work reduction $\Delta P$ will change as more MLI is resolved (all these quantities depend on the SI layer thickness and the velocity difference within the SI layer). Furthermore, the interaction between SI and MLI is neglected in this diagnostic study, where it could be approximated by resolving MLI and parameterizing SI in a simulation. A related work implementing the SI parameterization scheme proposed by Bachman et al. (2017) in the Coastal and Regional Ocean Community Model (CROCO) reveals that SI indeed modulates resolved MLI energetics (Dong et al. 2021). LES where both are resolved reveal intricate interplay (Hamlington et al. 2014). So the effects of partially resolving the seasonality of MLI on SI need to be rechecked in a higher resolution model, including parameterized or resolved SI. Dong et al. (2020b) recommend from 1.3 to $0.55 \mathrm{~km}$ for resolving MLI in half to $90 \%$ of the world in all seasons. A high resolution ocean model that can resolve both MLI and SI should be a better choice to study the impact of one on the other or their interactions.

Submesoscale motions are still strongly constrained by PV dynamics (e.g., Thomas 2005; Wenegrat et al. 2018b). For a high-resolution model that resolves SI, particular care needs to be taken when PV is evaluated, because PV can be spuriously noisy due to turbulent gridscale processes typical of forward energy cascades unless care is taken in the PV formulation and calculation (Bodner and Fox-Kemper 2020). Considering that SI mixes away negative PV, affecting both stratification at the bottom of the SI layer and surface conditions, the PV budget will differ between models that resolve SI and those do not. It remains unclear how different the PV sources and dissipation in SI-unresolved and unparameterized models (e.g., LLC4320 here) will be from those that parameterize and/or resolve SI. Unfortunately, direct evaluation of the PV budget in the LLC4320 cannot be conducted since turbulent mixing rate variables are unavailable.

The usable wind-work reduction estimated here is nominally a dissipation of wind work by SI. Presumably SI can change wind work more than this. As the resolution of ocean models becomes fine enough to resolve SI, the upper ocean current will be changed which potentially also modulates the wind work. One can reasonably expect that the wind work should be enhanced as the spatial resolution increases (e.g., Wang and Huang 2004; Flexas et al. 2019). Nonetheless, the SI role on this regime needs to be further clarified by SIresolving models.

As one of the main ocean mechanical energy sources, knowledge of the fate and dissipation of the wind power input to the ocean is always important for understanding ocean circulation dynamics and climate change (e.g., Wunsch and Ferrari 2004). The work here reveals a global magnitude of usable wind-work reduction comparable to the wind-work

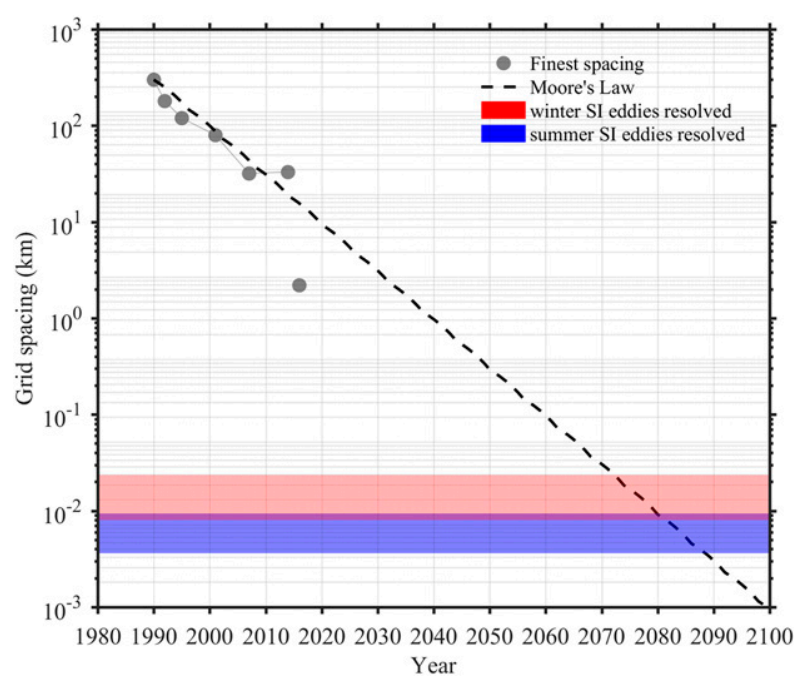

FIG. 9. Estimate of grid spacings of the IPCC ocean models. The gray dots denote the finest grid spacings reported by the IPCC reports by year of publication, except the latest one of the LLC4320 simulation (per Rocha et al. 2016b). The black line denotes the estimate predicted by the Moore's law, while the shaded regions denote the grid spacing intervals resolving $50 \%$ and $90 \%$ SI eddies in different seasons globally. This figure is reproduced based on Fig. 1 from Fox-Kemper et al. (2014) and Dong et al. (2020b).

input to the near-inertial frequency band (e.g., Flexas et al. 2019), implying a modulation role of SI on ocean currents and energy cascade. In addition to this, the variability of the SML thickness is also an important aspect for climate change. Different works have shown that SI restratifies the SML (e.g., Bachman and Taylor 2014; Dong et al. 2021). How big this contribution to the SML thickness is from a global perspective remains an outstanding question.

When the SI scale is compared with the global MLI scale estimated by Dong et al. (2020b), the SI scale is from one to two orders of magnitude smaller with median scales of 188 and $75 \mathrm{~m}$ in winter and summer globally. Following the work of Dong et al. (2020b), required grid spacings resolving SI eddies are calculated similarly and shown in Fig. $9(L / 8$, at least two grid cells per eddy radius). The finest ocean model grid spacings reported by the IPCC reports (gray dots) evolve roughly consistent with the estimated scaling of faster computing by Moore's law that predicts the model resolution doubling every six years (Moore 1965). The shaded regions in Fig. 9 denote the grid spacing intervals resolving SI eddies in $50 \%$ and $90 \%$ of regions globally. According to the estimated SI scale, the required grid spacings to resolve wintertime and summertime $50 \%$ SML eddies globally are 24 and $9.4 \mathrm{~m}$, respectively (upper bounds of red and blue intervals). The required grid spacings decrease to as low as $7.9 \mathrm{~m}$ in winter and $3.6 \mathrm{~m}$ in summer for 90\% SI eddies resolving (lower bounds of red and blue intervals). For the LLC4320 that analyzed here, the model is close to resolving wintertime MLI (Dong et al. 2020b), but almost a century more of exponential increase in computing power is needed to resolve SI globally (Fig. 9); even regional ocean models are unlikely resolve SI soon without dedicated efforts. 
Thus, parameterizations will be a primary tool in assessing the impacts of SI in the coming decades.

\section{b. Conclusions}

Based on the high-resolution global ocean model LLC4320, the scale and activity of SI are strongly seasonal and depend on latitude. Negative PV is ubiquitously observed in winter and the SI layer derived from the bulk PV is deepened up to $150 \mathrm{~m}$ in winter with a global proportion of $13 \%$ of boundary layer volume attributed to the SI-dominated layer versus the convective layer. The estimated median maximum SI scale varies with latitude from 568 to $23 \mathrm{~m}$. The median scale in winter is $188 \mathrm{~m}$ globally, about 2.5 times of that in summer $(75 \mathrm{~m})$. The required grid spacings to begin resolving winter and summer $50 \%$ SML eddies globally are 24 and $9.4 \mathrm{~m}$, respectively, and decrease to as low as $7.9 \mathrm{~m}$ in winter and $3.6 \mathrm{~m}$ in summer to resolve SI over $90 \%$ of Earth.

SI is more active in winter with a likelihood of $15 \%$ [11\%, $21 \%]$ over the globe compared $6 \%[4 \%, 12 \%]$ in summer based on a thickness ratio of $0.05[0.01,0.1]$. Hot spots for strong SI activity include the western Pacific and Atlantic Oceans, and the Southern Ocean. Where SI is present, the usable wind work is reduced due to SI dissipation. Over the globe, the averaged usable wind-work reduction due to SI in the two months is up to $0.83 \mathrm{~mW} \mathrm{~m}^{-2}$, with a proportion of $5 \%$ compared with the background global wind work of $16 \mathrm{~mW} \mathrm{~m}^{-2}$.

All these magnitudes are the maximums that SI can reach based on the specific two months (i.e., February and August in 2012). The results are expected to be sensitive to the variations of the surface forcing and limited by the short simulation window that is the focus here, which may not be representative of entire seasons for any given year and 2012 is surely not representative of all years. It is significant that spatially a nearly lognormal distribution for the usable wind-work reduction is found, which implies that spatial representativeness is a critical aspect of understanding the potential impacts of SI. Temporal representativeness is not examined in this study. For example, relatively larger mean wind velocities in the Southern Ocean and stronger wind variability in the tropics was believed to account for a larger wind work into the ocean in 2012 (Flexas et al. 2019), and tropical winds and Southern Ocean winds were known to have high variation due to ENSO and decadal climate change (Stocker et al. 2013). This work is not intended to imply urgency to include SI in climate models, but tries to clarify what to expect from SI. Up to now, submesoscales generated by MLI have been studied intensively benefiting from the supercomputer development (e.g., Boccaletti et al. 2007; Fox-Kemper et al. 2008; McWilliams 2016; Su et al. 2018). One can speculate that SI will become of increasing interest in the next stage of submesoscale studies, as resolving SI soon will occur in regional modeling at least.

Acknowledgments. The authors thank Christian E. Buckingham and an anonymous reviewer for their valuable comments and thoughtful suggestions. This work is supported by the National Key Research Program of China (2017YFA0604100). JHD acknowledges support from and the National Natural Science
Foundation of China (41806025) and the China Scholarship Council (201908320177). BFK acknowledges support from NSF OCE-1350795 and ONR N00014-17-1-2963. CMD appreciates the support from the National Key Research and Development Program of China (2016YFA0601803), Southern Marine Science and Engineering Guangdong Laboratory (Zhuhai) (SML2020SP007). The authors wish to thank the Estimating the Circulation and Climate of the Oceans (ECCO) team (https://ecco.jpl.nasa.gov) and NASA High-End Computing (HEC) from the NASA Advanced Superconducting (NAS) Division at the Ames Research Center for the LLC4320 simulation data. The LLC4320 data can be directly accessed from the ECCO Data Portal (https://data.nas.nasa.gov/ecco/ data.php), or conveniently downloaded using the xmitgcm package (https://xmitgcm.readthedocs.io/en/latest/index.html). The data for reproducing figures in this work are available at https:// doi.org/10.26300/w8zh-m226.

\section{REFERENCES}

Bachman, S. D., and J. R. Taylor, 2014: Modelling of partiallyresolved oceanic symmetric instability. Ocean Modell., 82, 15-27, https://doi.org/10.1016/j.ocemod.2014.07.006.

— B. Fox-Kemper, J. R. Taylor, and L. N. Thomas, 2017: Parameterization of frontal symmetric instabilities. I: Theory for resolved fronts. Ocean Model. Online, 109, 72-95, https:// doi.org/10.1016/j.ocemod.2016.12.003.

Balasubramanian, G., and M. K. Yau, 1994: Baroclinic instability in a two-layer model with parameterized slantwise convection. J. Atmos. Sci., 51, 971-990, https://doi.org/10.1175/15200469(1994)051<0971:BIIATL>2.0.CO;2.

Belcher, S. E., and Coauthors, 2012: A global perspective on Langmuir turbulence in the ocean surface boundary layer. Geophys. Res. Lett., 39, L18605, https://doi.org/10.1029/2012GL052932.

Bennetts, D. A., and B. Hoskins, 1979: Conditional symmetric instability-A possible explanation for frontal rainbands. Quart. J. Roy. Meteor. Soc., 105, 945-962, https://doi.org/ 10.1002/qj.49710544615.

Boccaletti, G., R. Ferrari, and B. Fox-Kemper, 2007: Mixed layer instabilities and restratification. J. Phys. Oceanogr., 37, 2228-2250, https://doi.org/10.1175/JPO3101.1.

Bodner, A., and B. Fox-Kemper, 2020: A breakdown in potential vorticity estimation delineates the submesoscale-to-turbulence boundary in large eddy simulations. J. Adv. Model. Earth Syst., 12, e2020MS002049, https://doi.org/10.1029/2020MS002049.

Buckingham, C. E., and Coauthors, 2016: Seasonality of submesoscale flows in the ocean surface boundary layer. Geophys. Res. Lett., $\mathbf{4 3}$, 2118-2126, https://doi.org/10.1002/2016GL068009.

— mesoscale processes to turbulence in the open ocean surface boundary layer. J. Adv. Model. Earth Syst., 11, 4066-4094, https://doi.org/10.1029/2019MS001801.

, J. Gula, and X. Carton, 2021a: The role of curvature in modifying frontal instabilities. Part I: Review of theory and presentation of a nondimensional instability criterion. J. Phys. Oceanogr., 51, 299-315, https://doi.org/10.1175/JPO-D-190265.1 .

$\ldots, \ldots$, and $-2021 \mathrm{~b}$ : The role of curvature in modifying frontal instabilities. Part II: Application of the criterion to curved density fronts at low Richardson numbers. J. Phys. Oceanogr., 51, 317-341, https://doi.org/10.1175/JPO-D-200258.1. 
Callies, J., R. Ferrari, J. M. Klymak, and J. Gula, 2015: Seasonality in submesoscale turbulence. Nat. Commun., 6, 6862, https:// doi.org/10.1038/ncomms7862.

— , G. Flierl, R. Ferrari, and B. Fox-Kemper, 2016: The role of mixed-layer instabilities in submesoscale turbulence. J. Fluid Mech., 788, 5-41, https://doi.org/10.1017/jfm.2015.700.

Capet, X., J. C. McWilliams, M. J. Molemaker, and A. Shchepetkin, 2008: Mesoscale to submesoscale transition in the California Current System. Part I: Flow structure, eddy flux, and observational tests. J. Phys. Oceanogr., 38, 29-43, https://doi.org/ 10.1175/2007JPO3671.1.

Colin de Verdière, A., 2012: The stability of short symmetric internal waves on sloping fronts: Beyond the traditional approximation. J. Phys. Oceanogr., 42, 459-475, https://doi.org/ 10.1175/JPO-D-11-067.1.

D'Asaro, E., C. Lee, L. Rainville, R. Harcourt, and L. Thomas, 2011: Enhanced turbulence and energy dissipation at ocean fronts. Science, 332, 318-322, https://doi.org/10.1126/ science.1201515.

de Boyer Montégut, C., G. Madec, A. S. Fischer, A. Lazar, and D. Iudicone, 2004: Mixed layer depth over the global ocean: An examination of profile data and a profile-based climatology. J. Geophys. Res., 109, C12003, https://doi.org/10.1029/2004JC002378.

Dong, J., and Y. Zhong, 2018: The spatiotemporal features of submesoscale processes in the northeastern South China Sea. Acta Oceanol. Sin., 37, 8-18, https://doi.org/10.1007/s13131018-1277-2.

—, B. Fox-Kemper, H. Zhang, and C. Dong, 2020a: The seasonality of submesoscale energy production, content, and cascade. Geophys. Res. Lett., 47, e2020GL087388, https:// doi.org/10.1029/2020GL087388.

,,$-- \ldots$, and,$- 2020 \mathrm{~b}$ : The scale of baroclinic instability globally. J. Phys. Oceanogr., 50, 2649-2667, https://doi.org/ 10.1175/JPO-D-20-0043.1.

—_, _- J. Zhu, and C. Dong, 2021: Application of symmetric instability parameterization in the Coastal and Regional Ocean Community Model (CROCO). J. Adv. Model. Earth Syst., 13, e2020MS002302, https://doi.org/ 10.1029/2020MS002302.

Duhaut, T. H. A., and D. N. Straub, 2006: Wind stress dependence on ocean surface velocity: Implications for mechanical energy input to ocean circulation. J. Phys. Oceanogr., 36, 202-211, https://doi.org/10.1175/JPO2842.1.

Du Plessis, M., S. Swart I. J. Ansorge, A. Mahadevan, and A. F. Thompson, 2019: Southern Ocean seasonal restratification delayed by submesoscale wind-front interactions. J. Phys. Oceanogr., 49, 1035-1053, https://doi.org/10.1175/JPO-D-180136.1.

Fei, J., R. Wu, X. Huang, Y. Wang, and X. Cheng, 2011: Development of an integrated vertical-slantwise convective parameterization scheme and its associated numerical experiments. Acta Meteor. Sin., 25, 405-418, https://doi.org/10.1007/ s13351-011-0402-3.

Ferrari, R., and C. Wunsch, 2009: Ocean circulation kinetic energy: Reservoirs, sources, and sinks. Annu. Rev. Fluid Mech., 41, 253-282, https://doi.org/10.1146/annurev.fluid.40.111406.102139.

Flexas, M. M., A. F. Thompson, H. S. Torres, P. Klein, J. T. Farrar, H. Zhang, and D. Menemenlis, 2019: Global estimates of the energy transfer from the wind to the ocean, with emphasis on near-inertial oscillations. J. Geophys. Res. Oceans, 124, 57235746, https://doi.org/10.1029/2018JC014453.

Forget, G., J.-M. Campin, P. Heimbach, C. N. Hill, R. M. Ponte, and C. Wunsch, 2015: ECCO version 4: An integrated framework for non-linear inverse modeling and global ocean state estimation. Geosci. Model Dev., 8, 3071-3104, https:// doi.org/10.5194/gmd-8-3071-2015.

Fox-Kemper, B., R. Ferrari, and R. Hallberg, 2008: Parameterization of mixed layer eddies. Part I: Theory and diagnosis. J. Phys. Oceanogr., 38,1145-1165, https://doi.org/10.1175/2007JPO3792.1. , and Coauthors, 2011: Parameterization of mixed layer eddies. III: Implementation and impact in global ocean climate simulations. Ocean Model. Online, 39, 61-78, https://doi.org/ 10.1016/j.ocemod.2010.09.002.

— S. Bachman, B. Pearson, and S. Reckinger, 2014: Principles and advances in subgrid modelling for eddy-rich simulations. CLIVAR Exchanges, No. 19, International CLIVAR Project Office, Southampton, United Kingdom, 42-46.

Gommenginger, C., and Coauthors, 2019: SEASTAR: A mission to study ocean submesoscale dynamics and small-scale atmosphere-ocean processes in coastal, shelf and polar seas. Front. Mar. Sci., 6, 457, https://doi.org/10.3389/fmars.2019.00457.

Haine, T. W., and J. Marshall, 1998: Gravitational, symmetric, and baroclinic instability of the ocean mixed layer. J. Phys. Oceanogr., 28, 634-658, https://doi.org/10.1175/ 1520-0485(1998)028<0634:GSABIO >2.0.CO;2.

Hamlington, P. E., L. P. Van Roekel, B. Fox-Kemper, K. Julien, and G. P. Chini, 2014: Langmuir-submesoscale interactions: Descriptive analysis of multiscale frontal spindown simulations. J. Phys. Oceanogr., 44, 2249-2272, https://doi.org/ 10.1175/JPO-D-13-0139.1.

Haney, S., and Coauthors, 2012: Hurricane wake restratification rates of one-, two- and three-dimensional processes. J. Mar. Res., 70, 824-850, https://doi.org/10.1357/002224012806770937.

— B. B. Fox-Kemper, K. Julien, and A. Webb, 2015: Symmetric and geostrophic instabilities in the wave-forced ocean mixed layer. J. Phys. Oceanogr., 45, 3033-3056, https://doi.org/ 10.1175/JPO-D-15-0044.1.

Hoskins, B., 1974: The role of potential vorticity in symmetric stability and instability. Quart. J. Roy. Meteor. Soc., 100, 480-482, https://doi.org/10.1002/qj.49710042520.

Hughes, C. W., and C. Wilson, 2008: Wind work on the geostrophic ocean circulation: An observational study of the effect of small scales in the wind stress. J. Geophys. Res., 113, C02016, https:// doi.org/10.1029/2007JC004371.

Jeffery, N., and B. Wingate, 2009: The effect of tilted rotation on shear instabilities at low stratifications. J. Phys. Oceanogr., 39, 3147-3161, https://doi.org/10.1175/2009JPO4138.1.

Large, W. G., J. C. McWilliams, and S. C. Doney, 1994: Oceanic vertical mixing: A review and a model with a nonlocal boundary layer parameterization. Rev. Geophys., 32, 363-403, https://doi.org/10.1029/94RG01872.

Li, Q., and B. Fox-Kemper, 2017: Assessing the effects of Langmuir turbulence on the entrainment buoyancy flux in the ocean surface boundary layer. J. Phys. Oceanogr., 47, 2863-2886, https://doi.org/10.1175/JPO-D-17-0085.1.

_- A. Webb, B. Fox-Kemper, A. Craig, G. Danabasoglu, W. G. Large, and M. Vertenstein, 2016: Langmuir mixing effects on global climate: WAVEWATCH III in CESM. Ocean Model. Online, 103, 145-160, https://doi.org/10.1016/ j.ocemod.2015.07.020.

Lindstrom, S. S., and T. E. Nordeng, 1992: Parameterized slantwise convection in a numerical model. Mon. Wea. Rev., 120, 742-756, https://doi.org/10.1175/1520-0493(1992)120<0742: PSCIAN $>2.0 . \mathrm{CO} ; 2$.

Little, H. J., M. Vichi, S. J. Thomalla, and S. Swart, 2018: Spatial and temporal scales of chlorophyll variability using high-resolution 
glider data. J. Mar. Syst., 187, 1-12, https://doi.org/10.1016/ j.jmarsys.2018.06.011.

McWilliams, J. C., 2016: Submesoscale currents in the ocean. Proc. Roy. Soc., A472, 20160117, https://doi.org/10.1098/rspa.2016.0117.

Melville, W. K., 1996: The role of surface-wave breaking in air-sea interaction. Annu. Rev. Fluid Mech., 28, 279-321, https:// doi.org/10.1146/annurev.fl.28.010196.001431.

Menemenlis, D., and Coauthors, 2008: ECCO2: High resolution global ocean and sea ice data synthesis. Mercator Ocean Quarterly Newsletter, No. 31, Mercator Ocean International, Ramonville-Saint-Agne, France, 13-21.

Mensa, J. A., Z. Garraffo, A. Griffa, T. M. Özgökmen, A. Haza, and M. Veneziani, 2013: Seasonality of the submesoscale dynamics in the Gulf Stream region. Ocean Dyn., 63, 923-941, https://doi.org/10.1007/s10236-013-0633-1.

Moore, G. E., 1965: Cramming more components onto integrated circuits. Electronics, 38, 114-116.

Noh, Y., H. Ok, E. Lee, T. Toyoda, and N. Hirose, 2016: Parameterization of Langmuir circulation in the ocean mixed layer model using LES and its application to the OGCM. J. Phys. Oceanogr., 46, 57-78, https://doi.org/10.1175/JPO-D14-0137.1.

Pearson, B., and B. Fox-Kemper, 2018: Log-normal turbulence dissipation in global ocean models. Phys. Rev. Lett., 120, 094501, https://doi.org/10.1103/PhysRevLett.120.094501.

Qiao, F., Y. Yuan, Y. Yang, Q. Zheng, C. Xia, and J. Ma, 2004: Wave-induced mixing in the upper ocean: Distribution and application to a global ocean circulation model. Geophys. Res. Lett., 31, L11303, https://doi.org/10.1029/2004GL019824.

— - _ J. Jeng, D. Dai, and Z. Song, 2016: Wave-turbulence interaction-induced vertical mixing and its effects in ocean and climate models. Philos. Trans. Roy. Soc., 374A, 20150201, https://doi.org/10.1098/rsta.2015.0201.

Ramachandran, S., and Coauthors, 2018: Submesoscale processes at shallow salinity fronts in the Bay of Bengal: Observations during the winter monsoon. J. Phys. Oceanogr., 48, 479-509, https://doi.org/10.1175/JPO-D-16-0283.1.

Renault, L., J. C. McWilliams, and J. Gula, 2018: Dampening of submesoscale currents by air-sea stress coupling in the Californian upwelling system. Sci. Rep., 8, 13388, https://doi.org/10.1038/ s41598-018-31602-3.

Rocha, C. B., S. T. Gille, T. K. Chereskin, and D. Menemenlis, 2016a: Seasonality of submesoscale dynamics in the Kuroshio Extension. Geophys. Res. Lett., 43, 11304-11311, https:// doi.org/10.1002/2016GL071349.

, T. K. Chereskin, S. T. Gille, and D. Menemenlis, 2016b: Mesoscale to submesoscale wavenumber spectra in Drake Passage. J. Phys. Oceanogr., 46, 601-620, https://doi.org/ 10.1175/JPO-D-15-0087.1.

Sarkar, S., H. T. Pham, S. Ramachandran, J. D. Nash, A. Tandon, J. Buckley, A. A. Lotliker, and M. M. Omand, 2016: The interplay between submesoscale instabilities and turbulence in the surface layer of the Bay of Bengal. Oceanography, 29 (2), 146-157, https://doi.org/10.5670/oceanog.2016.47.

Sasaki, H., P. Klein, Y. Sasai, and B. Qiu, 2017: Regionality and seasonality of submesoscale and mesoscale turbulence in the North Pacific Ocean. Ocean Dyn., 67, 1195-1216, https:// doi.org/10.1007/s10236-017-1083-y.

Savelyev, I., and Coauthors, 2018: Aerial observations of symmetric instability at the north wall of the Gulf Stream. Geophys. Res. Lett., 45, 236-244, https://doi.org/10.1002/2017GL075735.

Schubert, R., J. Gula, R. J. Greatbatch, B. Baschek, and A. Biastoch, 2020: The submesoscale kinetic energy cascade:
Mesoscale absorption of submesoscale mixed layer eddies and frontal downscale fluxes. J. Phys. Oceanogr., 50, 2573-2589, https://doi.org/10.1175/JPO-D-19-0311.1.

Stamper, M. A., and J. R. Taylor, 2017: The transition from symmetric to baroclinic instability in the Eady model. Ocean Dyn., 67, 65-80, https://doi.org/10.1007/s10236-016-1011-6.

Stocker, T. F., and Coauthors, 2013: Technical summary. Climate Change 2013: The Physical Science Basis, T. F. Stocker et al., Eds., Cambridge University Press, 33-115.

Stone, P. H., 1966: On non-geostrophic baroclinic stability. J. Atmos. Sci., 23, 390-400, https://doi.org/10.1175/15200469(1966)023<0390:ONGBS $>2.0$.CO;2.

Su, Z., J. Wang, P. Klein, A. F. Thompson, and D. Menemenlis, 2018: Ocean submesoscales as a key component of the global heat budget. Nat. Commun., 9, 775, https://doi.org/10.1038/ s41467-018-02983-w.

Tandon, A., and C. Garrett, 1994: Mixed layer restratification due to a horizontal density gradient. J. Phys. Oceanogr., 24, 1419-1424, https://doi.org/10.1175/1520-0485(1994)024<1419: MLRDTA $>2.0 . \mathrm{CO} ; 2$.

—, and — 1995: Geostrophic adjustment and restratification of a mixed layer with horizontal gradients above a stratified layer. J. Phys. Oceanogr., 25, 2229-2241, https://doi.org/ 10.1175/1520-0485(1995)025<2229:GAAROA > 2.0.CO;2.

Taylor, J. R., and R. Ferrari, 2009: On the equilibration of a symmetrically unstable front via a secondary shear instability. J. Fluid Mech., 622, 103-113, https://doi.org/10.1017/ S0022112008005272.

$\longrightarrow$, and - 2010: Buoyancy and wind-driven convection at mixed layer density fronts. J. Phys. Oceanogr., 40, 1222-1242, https://doi.org/10.1175/2010JPO4365.1.

Thomas, L. N., 2005: Destruction of potential vorticity by winds. J. Phys. Oceanogr., 35, 2457-2466, https://doi.org/10.1175/ JPO2830.1.

2012: On the effects of frontogenetic strain on symmetric instability and inertia-gravity waves. J. Fluid Mech., 711, 620640, https://doi.org/10.1017/jfm.2012.416.

_- and J. Taylor, 2010: Reduction of the usable wind-work on the general circulation by forced symmetric instability. Geophys. Res. Lett., 37, L18606, https://doi.org/10.1029/ 2010GL044680.

—, A. Tandon, and A. Mahadevan, 2008: Submesoscale processes and dynamics. Ocean Modeling in an Eddying Regime, Geophys. Monogr., Vol. 177, Amer. Geophys. Union, https:// doi.org/10.1029/177GM04.

_, J. R. Taylor, R. Ferrari, and T. M. Joyce, 2013: Symmetric instability in the Gulf Stream. Deep-Sea Res. II, 91, 96-110, https://doi.org/10.1016/j.dsr2.2013.02.025.

,-- - E. A. D'Asaro, C. M. Lee, J. M. Klymak, and A. Shcherbina, 2016: Symmetric instability, inertial oscillations, and turbulence at the Gulf Stream front. J. Phys. Oceanogr., 46, 197-217, https://doi.org/10.1175/JPO-D-150008.1.

Thorpe, S., 2004: Langmuir circulation. Annu. Rev. Fluid Mech., 36, 55-79, https://doi.org/10.1146/annurev.fluid.36.052203.071431.

Viglione, G. A., A. F. Thompson, M. M. Flexas, J. Sprintall, and S. Swart, 2018: Abrupt transitions in submesoscale structure in southern Drake Passage: Glider observations and model results. J. Phys. Oceanogr., 48, 2011-2027, https://doi.org/10.1175/ JPO-D-17-0192.1.

Wang, W., and R. X. Huang, 2004: Wind energy input to the Ekman layer. J. Phys. Oceanogr., 34, 1267-1275, https://doi.org/10.1175/ 1520-0485(2004)034<1267:WEITTE >2.0.CO;2. 
Wenegrat, J. O., and L. N. Thomas, 2017: Ekman transport in balanced currents with curvature. J. Phys. Oceanogr., 47, 1189-1203, https://doi.org/10.1175/JPO-D-16-0239.1.

— , and - 2020: Centrifugal and symmetric instability during Ekman adjustment of the bottom boundary layer. J. Phys. Oceanogr., 50, 1793-1812, https://doi.org/10.1175/JPO-D-200027.1.

_ J J. Callies, and L. N. Thomas, 2018a: Submesoscale baroclinic instability in the bottom boundary layer. J. Phys. Oceanogr., 48, 2571-2592, https://doi.org/10.1175/JPO-D-17-0264.1.

_ L. N. Thomas, J. Gula, and J. C. McWilliams, 2018b: Effects of the submesoscale on the potential vorticity budget of ocean mode waters. J. Phys. Oceanogr., 48, 2141-2165, https:// doi.org/10.1175/JPO-D-17-0219.1.

Wunsch, C., and R. Ferrari, 2004: Vertical mixing, energy, and the general circulation of the oceans. Annu. Rev. Fluid Mech., 36, 281-314, https://doi.org/10.1146/annurev.fluid.36.050802.122121.

—, P. Heimbach, R. Ponte, and I. Fukumori, 2009: The global general circulation of the ocean estimated by the ECCOconsortium. Oceanography, 22 (2), 88-103, https://doi.org/ 10.5670/oceanog.2009.41.

Yankovsky, E., S. Legg, and R. W. Hallberg, 2020: Parameterization of submesoscale symmetric instability in dense flows along topography. Earth and Space Science Open Archive, https:// doi.org/10.1002/essoar.10503774.1.

Yu, X., A. C. Naveira Garabato, A. P. Martin, C. E. Buckingham, L. Brannigan, and Z. Su, 2019a: An annual cycle of submesoscale vertical flow and restratification in the upper ocean. J. Phys. Oceanogr., 49, 1439-1461, https://doi.org/10.1175/ JPO-D-18-0253.1.

, ——, ——, D. Gwyn Evans, and Z. Su, 2019b: Windforced symmetric instability at a transient mid-ocean front. Geophys. Res. Lett., 46, 11281-11291, https://oi.org/ 10.1029/2019GL084309.

Zhai, X., and R. J. Greatbatch, 2007: Wind work in a model of the northwest Atlantic Ocean. Geophys. Res. Lett., 34, L04606, https://doi.org/10.1029/2006GL028907.

—- H. L. Johnson, D. P. Marshall, and C. Wunsch, 2012: On the wind power input to the ocean general circulation. J. Phys. Oceanogr., 42, 1357-1365, https://doi.org/10.1175/ JPO-D-12-09.1.

Zhang, Z., X. Zhang, B. Qiu, W. Zhao, C. Zhou, X. Huang, and J. Tian, 2021: Submesoscale currents in the subtropical upper ocean observed by long-term high-resolution mooring arrays. J. Phys. Oceanogr., 51, 187-206, https://doi.org/10.1175/JPOD-20-0100.1. 